\title{
Ferritin Nanocages: A Novel Platform for Biomedical Applications
}

Article in Journal of Biomedical Nanotechnology · October 2014

DOI: $10.1166 / j b n .2014 .1980$

CITATIONS

17

6 authors, including:

\section{Bharat Bhushan}

The Ohio State University

1,135 PUBLICATIONS $\quad 40,575$ CITATIONS

SEE PROFILE

\section{Ishita Matai}

Indian Institute of Technology Roorkee

20 PUBLICATIONS 393 CITATIONS

SEE PROFILE

\section{READS}

496

\section{Uday Kumar}

Indian Institute of Technology Roorkee

23 PUBLICATIONS 318 CITATIONS

SEE PROFILE

Abhay Sachdev

Indian Institute of Technology Roorkee

23 PUBLICATIONS 428 CITATIONS

SEE PROFILE

Some of the authors of this publication are also working on these related projects:

Project

Project

Friction and durability of virgin and damaged skin with and without skin cream treatment using atomic force microscopy View project

Nanomedicine View project 


\title{
Ferritin Nanocages: A Novel Platform for Biomedical Applications
}

\author{
Bharat Bhushan ${ }^{1}$, S. Uday Kumar ${ }^{1}$, Ishita Matai ${ }^{1}$, Abhay Sachdev ${ }^{1}$, \\ Poornima Dubey ${ }^{1}$, and P. Gopinath ${ }^{1,2, *}$ \\ ${ }^{1}$ Nanobiotechnology Laboratory, Centre for Nanotechnology, Indian Institute of Technology Roorkee, Roorkee, Uttarakhand 247667, India \\ ${ }^{2}$ Department of Biotechnology, Indian Institute of Technology Roorkee, Roorkee, Uttarakhand 247667, India
}

\begin{abstract}
Ferritin is a ubiquitous iron storage protein responsible for maintaining the iron homeostasis in living organism and thereby protects the cell from oxidative damage. The ferritin protein cages have been used as a reaction vessel for the synthesis of various non-native metallic nanoparticles inside its core and also used as a nanocarrier for various applications. Lack of suitable non-viral carrier for targeted delivery of anticancer drugs and imaging agents is the major problem in cancer therapy and diagnosis. The $\mathrm{pH}$ dependent reversible assembling and disassembling property of ferritin renders it as a suitable candidate for encapsulating a variety of anticancer drugs and imaging probes. Ferritins external surface is chemically and genetically modifiable which can serve as attachment site for tumor specific targeting peptides or moieties. Recent studies, further establishes ferritin as a multifunctional nanocarrier for targeted cancer diagnosis and therapy. Moreover, the biological origin of these protein cages makes it a biocompatible nanocarrier that stabilizes and protects the enclosed particles from the external environment without provoking any toxic or immunogenic responses. This review mainly focuses on the application of ferritin nanocages as a novel non-viral nanocarrier for cancer therapy and it also highlights various biomedical applications of ferritin nanocages.
\end{abstract}

KEYWORDS: Apoferritin, Protein Cages, Nanoparticles Synthesis, Biomedical Applications, Cancer Therapy, Cancer Imaging.

\section{CONTENTS}

Introduction . . . . . . . . . . . . . . . . . . . . . 2950

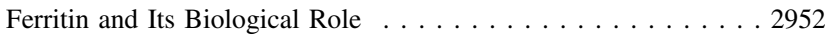

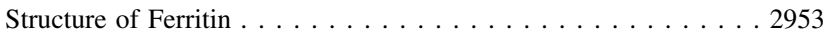

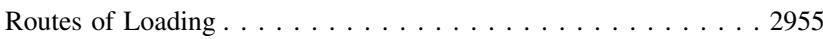

Biomineralization . . . . . . . . . . . . . . . . . . . 2955

Ferritin as a Template for Nanoparticles (NPs) Synthesis . . . . . 2956

Applications of Ferritin Protein Cages . . . . . . . . . . . . 2960

Tumor Therapy . . . . . . . . . . . . . . . . . . . . . . . . . . . 2960

Tumor Imaging . . . . . . . . . . . . . . . . . . . . . . . . . . . . . . . . . . . 2961

Tumor Targeting . . . . . . . . . . . . . . . . . . . 2963

Cellular Uptake . . . . . . . . . . . . . . . . . . . . . . . . . . . 2964

Bioassays . . . . . . . . . . . . . . . . . . . . . . . . . 2964

Biosensors . . . . . . . . . . . . . . . . . . . . . . 2965

Biocatalyst . . . . . . . . . . . . . . . . . . . . 2966

Enzyme Immobilization . . . . . . . . . . . . . . . . . . . 2967

Artificial Antioxidant . . . . . . . . . . . . . . . . . . . . . 2967

Magnetic Resonance Imaging (MRI)

Contrasting Agents . . . . . . . . . . . . . . . . 2967

Biocompatibility . . . . . . . . . . . . . . . . . . . . . . . . . . 2969

\footnotetext{
*Author to whom correspondence should be addressed.

Emails: pgopifnt@iitr.ernet.in, genegopi@gmail.com

Received: 20 January 2014

Accepted: 28 March 2014
}

\author{
Other Applications . . . . . . . . . . . . . . . . . . . . . . . . . 2969 \\ Conclusion and Future Perspectives . . . . . . . . . . . . . . . . 2970 \\ Acknowledgments . . . . . . . . . . . . . . . . . . . . . . . 2970 \\ References . . . . . . . . . . . . . . . . . . . . . . . . . . 2970
}

\section{INTRODUCTION}

Nanoscale materials play a vital role during the course of evolution of life in the form of nanosized biomolecules such as nucleic acids, lipids, carbohydrates and peptides. In the 20th century, nanotechnology and nanoscience has emerged as a fascinating area of research where many nanosized structures have proven their role in the specific field particularly in their biomedical aspects. ${ }^{1}$ Physical and chemical properties of nanoparticles such as size, shape, composition and surface chemistry determine the suitability of these particles for such applications., ${ }^{2,3}$

A variety of nanoscale materials, such as metal based nanoparticles, ${ }^{4-7}$ polymeric nanoparticles, ${ }^{8,9}$ magnetic nanoparticles, ${ }^{10,11}$ fluorescent nanoparticles, ${ }^{12-14}$ and nanocomposites, ${ }^{15,16}$ has been extensively synthesized and studied for their diagnosis and therapeutic roles. With 
increase in knowledge in this field, effective techniques are emerging against dreadful human diseases, particularly cancer in which conventional methods are not efficient. ${ }^{17,18}$ These nanostructures have comes out as blessing with disguise for human being as certain nanoparticles itself generate toxicity and become a major concern for human health. ${ }^{19}$ This provokes the researchers to search for more biocompatible nanostructured materials for therapeutic and diagnostic procedures. ${ }^{20,21}$
In this regard, biologically derived protein cage nanostructures emerge as potential nanoplatform in the development of theranostic (therapeutic and diagnostic) nanocarrier for the simultaneous delivery of anticancer and imaging agents. Protein cages get self-assembled from limited number of subunits to form a spherical nanocage having an interior cavity that is utilized for the storage of various therapeutic materials while exterior surface can be functionalized with tumor specific targeting moieties.

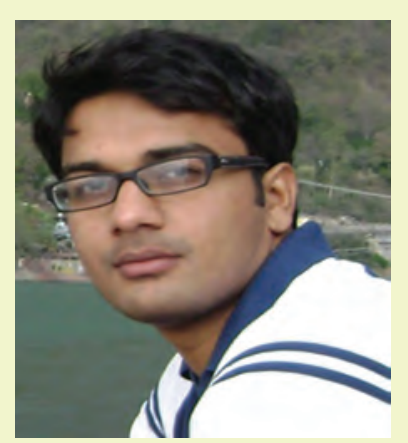

Bharat Bhushan received his B.Sc. degree in Industrial Chemistry and M.Sc. degree in Biotechnology from Aligarh Muslim University, India. Currently he is pursuing his Ph.D. degree from Centre for Nanotechnology, Indian Institute of Technology Roorkee, India. His research work focus on development of protein based nanocarriers for various biomedical applications.

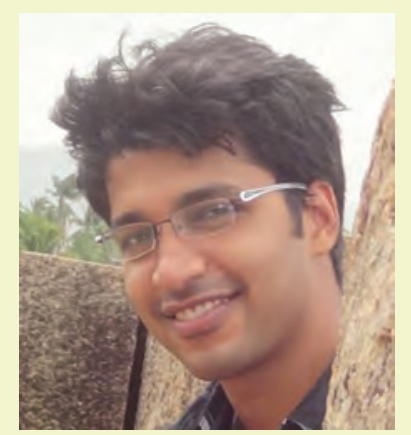

S. Uday Kumar is pursuing his doctoral degree from Centre for Nanotechnology, IIT Roorkee. At present he is involved in developing a multifunctional nanoscale carrier system for lung cancer theranostics. Apart from this, his work also includes fabrication of cell specific-tissue engineering scaffold systems wherein the theranostic systems can be evaluated. His research interest also includes tissue engineering and nanomedicine.

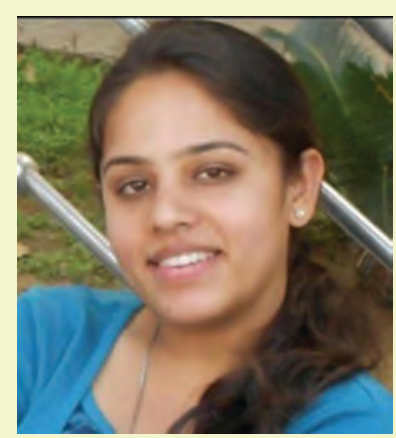

Ishita Matai received her M.Tech. in Nanotechnology from IIT Roorkee, India. She is currently a Ph.D. student in the Centre for Nanotechnology at IIT Roorkee, India. Her current research interests include developing multifunctional nanocomposites for targeted delivery of anticancer agents.

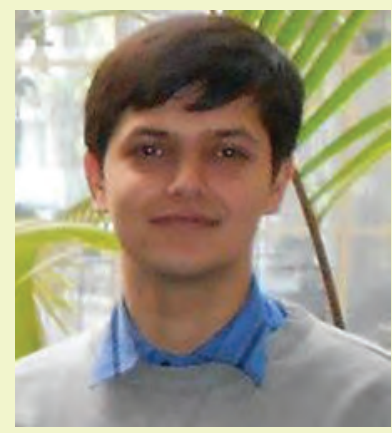

Abhay Sachdev received his M.Tech. in Nanotechnology from IIT Roorkee, India. Presently he is pursuing his Ph.D. in the Centre for Nanotechnology at IIT Roorkee, India. His research work focus on development of biocompatible imaging agents for bioimaging applications. 


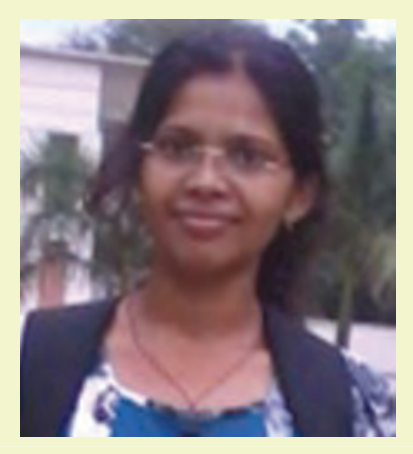

Poornima Dubey received her M.Sc. degree in Biotechnology from University of Mysore, India. Currently she is a Ph.D. student in the Centre for Nanotechnology at IIT Roorkee, India. She is investigating the molecular mechanism of toxicity of various nanoparticles and nanocomposites. Her research interests include nanotoxicology and cancer biology.

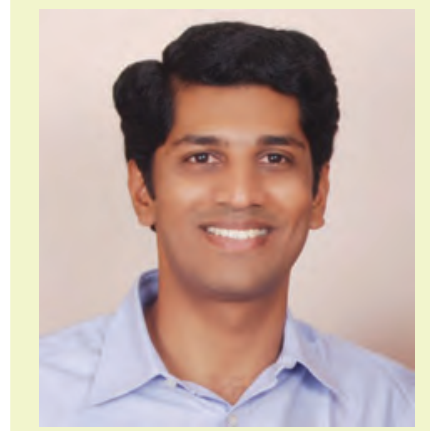

the closest extent.
P. Gopinath is an Assistant Professor in the Department of Biotechnology at Indian Institute of Technology (IIT) Roorkee, India. He received his B.Sc. degree in Microbiology and M.Sc. degree in Biotechnology from Bharathidasan University, India. He earned his Ph.D. in Biotechnology at Indian Institute of Technology Guwahati, India. He did his postdoctoral research at University of Rochester Medical Center, New York, USA. Currently his research group in nanobiotechnology laboratory is working on the development of various protein and polymer based nanocarriers for the delivery of various anticancer agents including anticancer drugs, siRNA, genes etc. This group is also exploring the possibilities of various biocompatible imaging agents for cancer diagnosis. In order to realize the efficacy of such therapeutic and imaging agents, they are validating these systems in an artificial scaffold which mimics the in vivo condition to
These nanoparticles overcome various limitations of conventional therapy such as non-specific distribution and targeting of drug, poor solubility of drug, poor bioavailability and therapeutic efficacy of drug.

The most commonly used protein nanocarrier includes ferritin, heat shock protein (Hsp), and viral nanoparticles such as cowpea chlorotic mottle virus (CCMV) and cowpea mosaic virus (CPMV), as discussed in the Table I. These protein nanocarriers have more advantages over other micrometer and sub-micrometer size delivery systems, such as liposome because the protein nanocarriers have high surface area to volume ratio which increases their drug holding capacity, enhance the solubility of drug, increases their bioavailability by controlled release of drug, biocompatible and do not produce any toxic effect due to its biological origin. ${ }^{41}$

Among the protein nanocarriers, viral nanoparticles are the most extensively studied protein cages. Several drawbacks have been coupled with the use of viral delivery vectors, which includes evoking immune response, probability of integrating with the host chromosome to produce a replication-competent infectious virus, rapid renal clearance from the body, difficulties in the modification of viral capsids for tumor specific targeted delivery and high cost of production. ${ }^{42}$ Thus more attention is given to non-viral protein cages as they offer advantages, such as less immunogenicity, larger drug/DNA holding capacity, not removed by the complement system, repeatedly administered without generating adverse effects, cheap, easily modifiable for targeted delivery and have negligible safety issues due to the non-viral nature of the delivery system. However, one disadvantage coupled with these nanocarriers is low transfection efficiency. So, most of the recent research has been focused on the development of novel non-viral nanoscale delivery system by utilizing the biologically originated protein cages having genetically controlled ordered structural symmetries and modifiable surface chemistries. Thus, by inducing genetic alterations various novel functionalities, such as multiple ligands, peptides and small chemical entities can be anchored to these nanocaged structures to make them competent for cancer theranostics and other biomedical applications.

In last few decades, the uses of biological nanoparticles, as nanocarriers become an emerging approach for the development of theranostic nanoparticles. Among these supramolecular assemblies of protein subunits, ferritins form a synthetic biomimetic platform for the sizeconstrained synthesis of nanomaterials. Thus this review summarizes the role of ferritin nanocages in the nanoparticles synthesis and also highlights their potential biomedical applications.

\section{FERRITIN AND ITS BIOLOGICAL ROLE}

In 1937, ferritin was first isolated from horse spleen $^{43}$ and later its crystal structure was elucidated in $1991 .{ }^{44}$ The ferritin superfamily has been divided into two main groups depending on their size namely: maxi-ferritin and mini-ferritin as described in Table II. Ferritin performs two major functions in the body. Firstly, they act as an 
Table I. Various types of protein cages, their structure and applications.

\begin{tabular}{|c|c|c|c|c|c|c|}
\hline $\begin{array}{l}\text { Protein } \\
\text { cages }\end{array}$ & $\begin{array}{l}\text { Interior } \\
\text { diameter }\end{array}$ & $\begin{array}{l}\text { Exterior } \\
\text { diameter }\end{array}$ & Structure & Properties and function & Applications & Refs. \\
\hline HSA & 8 & 12 & $\begin{array}{l}\text { Spherical shell composed of } \\
\text { 24-subunits, giving them octahedral } \\
(4: 3: 2) \text { symmetry. }\end{array}$ & $\begin{array}{l}\text { Disassemble at low } \mathrm{pH} \\
\text { and reassemble at } \\
\text { high } \mathrm{pH} \text {. }\end{array}$ & $\begin{array}{l}\text { Easily modifiable structure } \\
\text { used in cell targeting } \\
\text { and MRI imaging. }\end{array}$ & [22] \\
\hline Dps & 4.5 & 9 & $\begin{array}{l}\text { Spherical shell composed of } 12 \text { subunits } \\
\text { with } 23 \text { point group symmetry, along } \\
\text { with two type of } 3 \text { fold symmetry } \\
\text { channel having size } 0.7-0.9 \mathrm{~nm} \text {. }\end{array}$ & $\begin{array}{l}\text { Protect cell from oxidative } \\
\text { stress }\end{array}$ & $\begin{array}{l}\text { Template for synthesis of } \\
\text { variety of NPs. }\end{array}$ & {$[23,24]$} \\
\hline CCMV & 24 & 28 & $\begin{array}{l}\text { Capsid is composed of } 180 \text { copies of } 20 \\
\mathrm{kDa} \text { coat protein, which assemble into } \\
\text { a } T=3 \text { capsid with three positive } \\
\text { sense RNA molecules packaged } \\
\text { inside making a } 28 \mathrm{~nm} \text { virus and } 2 \mathrm{~nm} \\
\text { pores exist at the quasi } 3 \text {-fold axis. }\end{array}$ & $\begin{array}{l}\text { Capsids swell at } \mathrm{pH} \\
\text { greater than } 6.5 .\end{array}$ & $\begin{array}{l}\text { Easily modified by genetic } \\
\text { and chemical } \\
\text { modification and used in } \\
\text { MRI imaging, cell } \\
\text { targeting and imaging. }\end{array}$ & [25-27] \\
\hline Mj sHsp & 6.5 & 12 & $\begin{array}{l}\text { Composed of } 24 \text { subunits, which forms a } \\
\text { cage with cubic (4:3:2) symmetry and } \\
\text { with eight } 3 \mathrm{~nm} \text { pores located at the } 3 \\
\text { fold axes. Six smaller ( } 1.7 \mathrm{~nm} \text { ) pores } \\
\text { also exist at the } 4 \text {-fold axis. }\end{array}$ & $\begin{array}{l}\text { Extremely stable protein, } \\
\text { function as molecular } \\
\text { chaperones and over } \\
\text { expressed during stress. }\end{array}$ & $\begin{array}{l}\text { Easily modified, used to } \\
\text { deliver variety of } \\
\text { molecules such as MRI } \\
\text { contrasting agents etc. }\end{array}$ & [28-30] \\
\hline LS & 8 & 15 & $\begin{array}{l}\text { Hollow icosahedral shell with negatively } \\
\text { charged protein cavity, composed of } \\
60 \text { beta subunit and } 3 \text { alpha subunit. }\end{array}$ & $\begin{array}{l}\text { Enzyme involved in the } \\
\text { synthesis of lumazine, } \\
\text { a precursor of riboflavin }\end{array}$ & $\begin{array}{l}\text { Biomimetic packing of } \\
\text { GFP and HIV protease. }\end{array}$ & [31-33] \\
\hline TMV & 4 & 18 & $\begin{array}{l}\text { Contain ssRNA surrounded by } 300 \\
\mathrm{~nm} \times 18 \mathrm{~nm} \text { hollow protein tube, } \\
\text { composed of } 2130 \text { capsomer subunits } \\
\text { having both positively and negatively } \\
\text { charged amino acids on both surfaces } \\
\text { that act as the nucleation centres. }\end{array}$ & $\begin{array}{l}\text { Rod shaped and having } \\
\text { distinct amino acid } \\
\text { composition in interior } \\
\text { and exterior. }\end{array}$ & $\begin{array}{l}\text { pH dependent synthesis of } \\
\text { NPs. Used in synthesis } \\
\text { of nanotubes and other } \\
\text { nanoelectronic devices. }\end{array}$ & {$[34,35]$} \\
\hline P22 & 54 & 60 & $\begin{array}{l}\text { The mature phage form composed of } \\
415 \text { copies of } 46.6 \mathrm{kDa} \text { coat protein } \\
\text { assemble into a spherical } T=7 \\
\text { structure with as many as } 300 \text { of } 33 \\
\mathrm{kDa} \text { scaffold protein. } 10 \mathrm{~nm} \text { pores are } \\
\text { present in the P22 capsid. }\end{array}$ & $\begin{array}{l}\text { P22 naturally infects } \\
\text { Salmonella typhimurium }\end{array}$ & $\begin{array}{l}\text { Easily modified by } \\
\text { attaching functional } \\
\text { moieties such as biotin } \\
\text { to encapsulate variety of } \\
\text { particles. }\end{array}$ & {$[36,37]$} \\
\hline MS2 & 23 & 27 & $\begin{array}{l}\text { Self assembled structure composed of } \\
180 \text { subunit having } 32 \text { pores of } \\
\text { diameter } 1.8 \mathrm{~nm} \text {. }\end{array}$ & Infect E.coli & $\begin{array}{l}\text { Easily modifiable, used to } \\
\text { deliver variety of } \\
\text { molecules, such as } \\
\text { imaging agent for PET } \\
\text { and MRI. }\end{array}$ & [38-40] \\
\hline
\end{tabular}

Notes: HSA-Horse spleen apoferritin; Dps-DNA-binding protein from starved cells; CCMV-Cowpea chlorotic mottle virus; Mj sHsp-Heat shock protein from Methanococcus jannaschii; LS-Lumazine synthase from Bacillus subtilis; TMV-Tobacco mosaic virus; P22-P22-Bacteriophage; MS2-MS2 Bacteriophage.

iron storage component and thereby maintain the availability of iron during biological synthesis of various proteins, which comprise iron as co-factor (such as heme protein, iron sulfur protein ( $\mathrm{Fe}$-porphyrin, $\mathrm{Fe}-\mathrm{S}$, and $\mathrm{Fe})$ ). These iron-containing proteins constitute a crucial component in various biological processes, such as respiration, photosynthesis and play an important role in hydroxylation reactions and oxygen sensing. ${ }^{57,58}$ Secondly, ferritins play a vital role in the iron metabolism and protect the cells from oxidative damage. ${ }^{22,59}$

\section{STRUCTURE OF FERRITIN}

The primary amino acid sequences of the ferritins does not have any homological similarities however a clear structural homology were found at the $2^{\circ}, 3^{\circ}$, and $4^{\circ}$ levels, indicating that the structure of ferritins remain conserved during the evolution. The structure of ferritin is shown in Figure 1 having 24 identical subunits with octahedral symmetry. These subunits possess a four-helix bundle along with a fifth $\mathrm{E}$ helix which is found at $60^{\circ}$ to the fourhelix bundle axis. ${ }^{44,61,62}$ Ferritin is a spherical hollow protein cage with internal and external diameter of about $120 \AA$ and $75 \AA$, respectively. ${ }^{63}$ It can accumulate and store approximately 4500 iron atoms.

The apoferritin protein cage is composed of $80-90 \%$ of L-chain (light chain) and 10-20\% of H-chain (heavy chain) subunits with $55 \%$ sequence homology. The difference between these two subunits lies in their outer surface, cavity, and hydrophobic channel sequences whereas the hydrophilic channel sequence found to be identical. ${ }^{64,65}$ The negatively charged $\mathrm{L}$ chain subunit found inside the 
Table II. Difference between maxi-ferritin and mini-ferritin.

\begin{tabular}{|c|c|c|c|}
\hline Characteristics & Maxi-ferritin & Mini-ferritin & References \\
\hline Size & $8-12 \mathrm{~nm}$ & $4.5-9 \mathrm{~nm}$ & {$[23]$} \\
\hline Structure & $\begin{array}{l}\text { - } 24 \text { subunits }(\sim 20 \mathrm{kDa}) \text {, four-helix bundle fold, } \\
\text { with octahedral symmetry ( } 432 \text { point group } \\
\text { symmetry) forming a larger spherical cavity that } \\
\text { accumulate } 4500 \mathrm{Fe} \text { atoms. } \\
\text { - Monomer is made up of a four-helix bundle } \\
\text { (A, B, C and D helices) with a short fifth helix } \\
\text { (E helix) at the } C \text {-terminus. } \\
\text { - Each subunit interacts with six adjacent } \\
\text { monomers through three types of } \\
\text { symmetry-related interfaces. } \\
\text { - There are twelve dimerization interaction } \\
\text { interfaces at the two-fold axes, eight } \\
\text { trimerization interaction interfaces at the } \\
\text { three-fold axes and six tetramerization } \\
\text { interfaces at the four-fold axes. }\end{array}$ & $\begin{array}{l}\text { - } 12 \text { subunits, four-helix bundle fold with } 32 \\
\text { (tetrahedral) point group symmetry forming a } \\
\text { smaller cavity that accumulate } 500 \text { Fe atoms and is } \\
\text { a structural analogue of the maxi-ferritins. } \\
\text { - Monomer folds into a four-helix bundle (A, B, C and } \\
\text { D helices), with no } \mathrm{E} \text { helix } \\
\text { - Each subunit interacts with five surrounding } \\
\text { monomers through two types of symmetry-related } \\
\text { protein-protein interfaces. } \\
\text { - Six dimer interactions are at two-fold symmetry } \\
\text { axes, and four trimerization interactions are } \\
\text { centered at the three-fold axes. Two types of } \\
\text { nonequivalent three-fold interfaces exist in the } \\
\text { mini-ferritin tetrahedral dodecamer. }\end{array}$ & {$[23,44-46]$} \\
\hline Occurrence & Bacteria, archaea, and eukaryotes & Bacteria and archaea & \\
\hline Examples & Human ferritin, HSA, bacterioferritins & Dps & \\
\hline Function & $\begin{array}{l}\text { Store excess iron and protect from oxidative } \\
\text { stress by removing iron and oxygen, } \\
\text { predominantly dioxygen. }\end{array}$ & $\begin{array}{l}\text { Protecting bacteria from oxidative damage by } \\
\text { removing iron and oxygen, predominantly hydrogen } \\
\text { peroxide. }\end{array}$ & [47] \\
\hline $\begin{array}{l}\text { Ferrioxidase } \\
\text { site/active site }\end{array}$ & $\begin{array}{l}\text { - Located in the middle of the monomeric } \\
\text { four-helix bundle. } \\
\text { - } 24 \text { active sites are saturated with } 48 \mathrm{Fe}(\mathrm{II}) \text {. }\end{array}$ & $\begin{array}{l}\text { - Situated at the interface between two-fold } \\
\text { axis-related monomers. } \\
\text { - } 12 \text { active sites are saturated with } 12 \mathrm{Fe} \text { (II) atoms. } \\
\text { Except in proteins that can use dioxygen as the } \\
\text { substrate, where } 24 \mathrm{Fe} \text { (II) bind/cage. }\end{array}$ & {$[23,48,49]$} \\
\hline Stability & $\begin{array}{l}\text { Highly resistant to chemical denaturation, } \mathrm{pH} \\
\text { changes and heat. Stable in dimer form in } \\
\text { solution and assembly proceed from dimers to } \\
\text { tetramers and octamers. }\end{array}$ & $\begin{array}{l}\text { The protein was found to be extremely } \mathrm{pH} \text { stable, } \\
\text { Dps dissociated reversibly into dimers at conditions } \\
\text { above } \mathrm{pH} 7.5 \text { and below } 6.0 \text {. Furthermore, dimers } \\
\text { dissociate to monomers at } \mathrm{pH} 4.0 \text {. }\end{array}$ & [50-53] \\
\hline Self assembly & $\begin{array}{l}6 \text { amino acids at the end of the } C \text {-terminal tip of } \\
\text { the } D \text { helix are essential for self-assembly. }\end{array}$ & $\begin{array}{l}26 \text { residues of the } C \text {-terminus are essential for } \\
\text { self-assembly. }\end{array}$ & {$[54]$} \\
\hline Iron entry & $\begin{array}{l}\text { The channel carboxylates in } 24 \text { subunit ferritins } \\
\text { selectively control Fe2+ entry. }\end{array}$ & $\begin{array}{l}\text { The channel carboxylate groups control both } \mathrm{Fe} 2+ \\
\text { entry and } \mathrm{Fe} 2+\text { exit. }\end{array}$ & {$[55,56]$} \\
\hline
\end{tabular}

inner cavity of assembled protein cage has clusters of acidic residues (Glu and Asp) which form the mineral nucleation site. This site mainly performs the function of delivery of iron and help in the nucleation of ferrihydrite core. ${ }^{61,66}$ So, these chains were found in the extra cellular ferritin as they act as an iron carrier for different cells. ${ }^{67}$ The heavy chain which catalyzed the oxidation of $\mathrm{Fe}^{+2}$ is
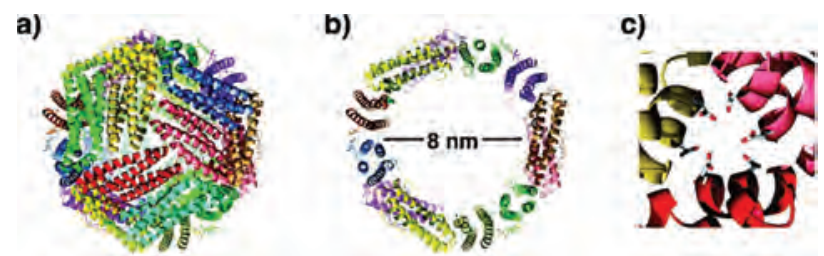

Figure 1. (a)-(c) Ribbon diagrams of L-ferritin taken from PDB entry 1DAT: (a) the 24-subunit assembled cage; (b) the inner cavity; (c) the 3-fold axis channel. Reprinted with permission from [60], S. Abe, et al., Polymerization of phenylacetylene by rhodium complexes within a discrete space of apo-ferritin. J. Am. Chem. Soc. 131, 6958 (2009). () 2009, American Chemical Society. responsible for the iron mineralization and the formation of iron crystal. ${ }^{65}$ The nucleation site of $\mathrm{H}$ chain subunit found in close proximity with the ferroxidase site sharing one glutamate residue between them. ${ }^{61}$ Recent studies on different ferritin further strengthened that iron storing capability of ferritin is related to the number of $\mathrm{L}$ subunits. Moreover, presence of small number of $\mathrm{H}$ subunit in ferritin obtained from iron storage organ reveal the importance of oxidative process in iron storage. ${ }^{68}$ The ferroxidase activity of the apoferritin gets affected in the presence of metal nanoparticles as it has been found to get increased in the presence of platinum, gold and silver nanoparticles. 69,70

There are 14 channels having a diameter of $0.3-0.4 \mathrm{~nm}$ each, which are present at the junction of these subunits. Out of these 14 channels, eight channels are hydrophilic in nature and posses four-fold symmetry, while the remaining six are hydrophobic and possess three-fold symmetry. ${ }^{71}$ The aperture size of these hydrophilic channels are adjusted according to the particles as demonstrated that in presence of urea, these eight hydrophilic channels 
attain sufficient flexibility and allow larger size molecules to penetrate inside the apoferritin cavity. ${ }^{72}$

The molecular species enter into the protein cavity through these channels by charge selective process. Moreover, flow of ion through the pore is regulated by the local folding and unfolding of the ion channel pore. The four highly conserved residues, such as arginine 72 , aspartate 122, leucine 110 and leucine 134 are responsible for the stability of pore and form the pore gate. These pores are less stable compared to the overall stability of ferritin nanocages, even at low temperature and low concentration of denaturants, such as urea and guanidine, pores show instability. It has been suggested that biological regulators are present in vivo, which recognize the pore gates and hold it in either open or close conformation to maintain the iron homeostasis. ${ }^{73}$ Ferritin cage without the ferrihydrite mineral core is called as apoferritin.

\section{ROUTES OF LOADING}

There are two major ways of loading materials inside apoferritin as shown in Scheme 1: First, by directly incubating the materials with the apoferritin in which the smaller particles comparable to the size of channels move directly and get accumulated inside the inner cavity. This process mimics the natural biomineralization process. Second way is applicable for the larger particles which cannot efficiently pass through the channels. In this route, the apoferritin protein cage undergoes $\mathrm{pH}$ dependent assembly at higher $\mathrm{pH}$ and disassembly at lower $\mathrm{pH}$.

\section{BIOMINERALIZATION}

Ferritin protein cages have been used as nanosized containers for the controlled synthesis of a variety of nanoparticles by biomimetic process. So, in order to synthesize nanoparticles inside its cavity it becomes important to understand, how the process of biomineralization of iron naturally occurs in ferritin (Scheme 2).

Iron biomineralization in ferritin is a multistep process that includes:

1. Entry and binding of iron ions inside the ferritin cage cavity.

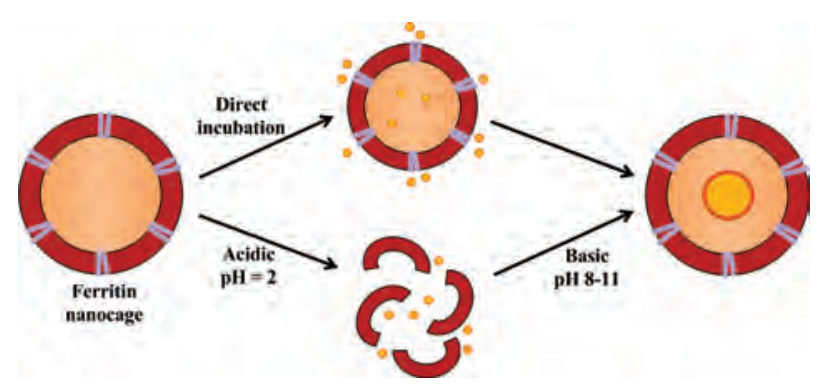

Scheme 1. Schematic representation of different routes of loading in ferritin nanocage.

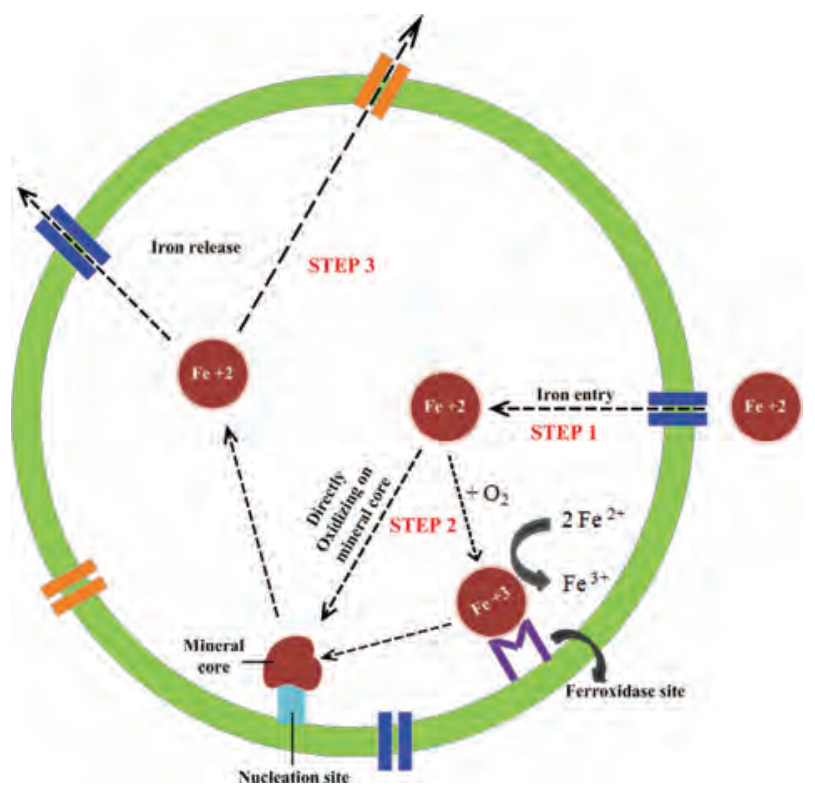

Scheme 2. Schematic representation of naturally occurring biomineralization process inside ferritin nanocage.

2. Oxidation of iron ions followed by nucleation and growth of ferrihydrite core.

3. Release of iron ions from ferritin.

Step 1. Entry and binding of iron ions inside the ferritin cage cavity. The iron enters into the ferritin through the $15 \AA$ long channels which are gated by extensions of the four-helix bundle subunits. These metal ions were guided inside the cavity by charged gradient of the channel created by the presence of conserved carboxylate residues: Glu130, Asp127, Ala26, Val42, Thr149. ${ }^{47,56}$ Moreover there are two basic types of functional channels present in ferritin:

(1) Iron ion entry channels formed by three subunits around the 3-fold cage axes which allows the passage of $\mathrm{Fe}^{2+}$ substrate to oxidoreductase sites (Asp127, Glu130).

(2) Iron ion nucleation channels, which are present at the other side of the 4-helix bundles subunit around the 4-fold cage axes (Ala26, Val42, Thr 149).

The $\mathrm{Fe}(\mathrm{II})$ ions reacts with $\mathrm{O}_{2}$ after binding to the active site and produce diferric oxo products in eukaryotes. The diferric peroxo intermediate (DFP) is first detectable intermediate which forms and decays in seconds or less into the di-Fe(III)O product, a mineral precursor which is later released into protein nucleation channels. ${ }^{48}$

Step 2. Oxidation of iron ions followed by nucleation and growth of ferrihydrite core. Two $\mathrm{Fe}^{2+}$ ions get oxidized to $\mathrm{Fe}^{3+}$ in the presence of oxygen after binding to the ferroxidase center. The $\mathrm{Fe}^{3+}$ ions then migrate to the ferritin inner cavity and finally a mineral core formation take places at the nucleation sites of the L-chain ferritin. This is the initial process when no iron is present in ferritin, but as soon as the iron mineral core is formed, the iron gets oxidized directly on the mineral core surface after 
passing through the 3 -fold channels. ${ }^{74}$ This oxidation process on mineral core is found to be more rapid than that at the ferroxidase center, which remains functional after a core is formed and with no significant contribution in $\mathrm{Fe}^{2+}$ oxidation. ${ }^{75}$

It has been shown by various in vitro studies using various mutant ferritin cage, which lack nucleation site or ferroxidase activity or both, directly affect the encapsulation or mineralization process or both. ${ }^{76}$ This indicates the role of nucleation site in aggregating the ions at the highly negatively charged protein interface and in facilitating oxidative mineralization and ferroxidase centre in converting the soluble $\mathrm{Fe}^{2+}$ to insoluble $\mathrm{Fe}^{3+}$, absence of which leads to the uncontrolled growth and precipitation. ${ }^{76,77}$ Thus suggests that the ferritin biomineralization is highly specific for iron. Step 3. Release of iron from ferritin. In vitro removal of iron from ferritin is a two-step process, which includes reduction of $\mathrm{Fe}^{3+}$ mineral followed by the chelation of $\mathrm{Fe}^{2+}$ from the mineral core. Four iron release reduction and chelation model namely subunit displacement, diffusion of molecules through the 3-fold channels, gated pores and electron transfer through the protein shell, has been briefly discussed in a review by Watt et al. ${ }^{78}$ Considering all the possible ways of iron release mechanism and their transportation through the protein cage, the 3-fold channels are currently accepted route for the passage of iron to enter and exit the protein cage. ${ }^{78}$ Moreover, the redox reactions occur during the iron mineralization and release are accompanied by the simultaneous release of ion in order to balance the charge on both sides of the cage. For example, the entries of electron during the reduction of iron in the mineral core are accompanied by concomitant release of negative charge from the core. Some of the important ions involved during this process are chloride and hydroxide ions, moving throughout the protein cage and phosphate ion release during the reduction process. ${ }^{78}$

Iron releasing occurs on exposure of ferritin to UV light or ionizing radiation, the iron mineral core acts as photoreceptor and result in the reduction of Fe (III). In the absence of oxygen, redox reaction results in the iron mobilization from ferritin catalyzed by the hydrated electron, which acts as a reducing agent. In the presence of oxygen superoxide radical anion $\left(\mathrm{O}_{2}^{--}\right)$is responsible for the iron release process. This suggests the requirement of an iron chelator for Fe(II) mobilization from ferritin, in the absence of which ferritin act as a electron-storage molecule. ${ }^{79}$ Moreover, the reversal of process of biomineralization is very slow, as shown in the in vitro study by removing the excess iron in sickle cell disease and thalassemia with the help of chelators. ${ }^{80,81}$

\section{FERRITIN AS A TEMPLATE FOR NANOPARTICLES (NPS) SYNTHESIS}

Metal nanoparticles can be fabricated inside the apoferritin cavity, which act as a reaction vessel. Protein cage like structure of apoferritin can be used for the size dependent encapsulation of various materials by serving as template to restrain the NPs growth and prevent aggregation. These self assembled protein shell form a reaction chamber for the synthesis of non-native materials of controlled dimensions, while exterior surface can be easily modified with various functional moieties through genetic and chemical modification. A variety of different precursor ions have been formed by nucleation and subsequent mineral growth suggesting that other non-native metals could also be mineralized within the ferritin core. Due to the sharper density of these NPs as compared to higher-dimensional structures, these NPs offer superior quality that can be used in biosensors, nanoelectronic devices, bioimaging and various other biomedical applications.

Artificial synthesis of ferromagnetic iron oxide nanoparticles inside the apoferritin cavity has been reported by Mann and co workers. ${ }^{82,83}$ They mimicked the natural biomineralization process and opened the way to utilize apoferritin for the synthesis of various inorganic nanoparticles. Similarly, mini-ferritin (Dps) used for the synthesis of NPs includes $\mathrm{Co}(\mathrm{O}) \mathrm{OH}$ and $\mathrm{Co}_{3} \mathrm{O}_{4}($ dia $4.34 \pm 0.55 \mathrm{~nm}),{ }^{84}$ $\gamma-\mathrm{Fe}_{2} \mathrm{O}_{3},{ }^{85,86} \mathrm{CdS}^{87}$ and $\mathrm{Pt}^{88}$

After loading, these NPs were undergoing various intermediate stages before leading to the final mineralized nanoparticles. Metal ions were reduced inside the cavity by using a reducing agent for example $\mathrm{H}_{2}, \mathrm{NaBH}_{4}$, or light, then the encapsulated NPs were separated from the unencapsulated ones by the implications of additional purification steps. ${ }^{89}$ Moreover the ferrihydrite core undergoes in situ reactions and gets modified to other iron products such as $\mathrm{FeO},{ }^{90}$ iron sulfide ${ }^{91}$ and semiconducting hematite $\left(\alpha-\mathrm{Fe}_{2} \mathrm{O}_{3}\right) .{ }^{92}$ Similarly, high temperature synthesis was carried out using ferritin from thermophilic archaeon Pyrococus furious, which retains its cage-like structure even at $120{ }^{\circ} \mathrm{C} .{ }^{93}$ This can be further used as a template for synthesis of magnetite ${ }^{94}$ and other metallic NPs such as gold, silver, lead, copper, nickel and semiconductors NPs such as CdS. The outer surface of ferritin modified with PEG prevents the bulk precipitation and improves the yield of NPs in ferritin cavity. ${ }^{95}$ The noble metals ions $\left(\mathrm{Au}^{3+}\right.$, $\mathrm{Ag}^{+}$) bind to the exterior surface of the protein. In order to facilitate internalization of these metal ions, reactive cysteine and histidine residues are removed from the exterior surface of ferritin and soft cysteine ligands are introduced in the interior surface. ${ }^{96}$ The metals ions bind to the specific binding site present on the protein shell, both interior and exterior surfaces of the protein cage that promote the growth of NPs both inside and outside the cage. Moreover, modification on the surface of ferritin leads to change in their properties. For instance, the alkylation of the ferritin protein using a monoamine-terminated alkane oligomer (dodecylamine) changes the charge of the protein and type of interactions by converting the primary carboxylic acid groups on the ferritin surface into hydrophobic groups. ${ }^{97}$ Recently, reported recombinant apoferritin 


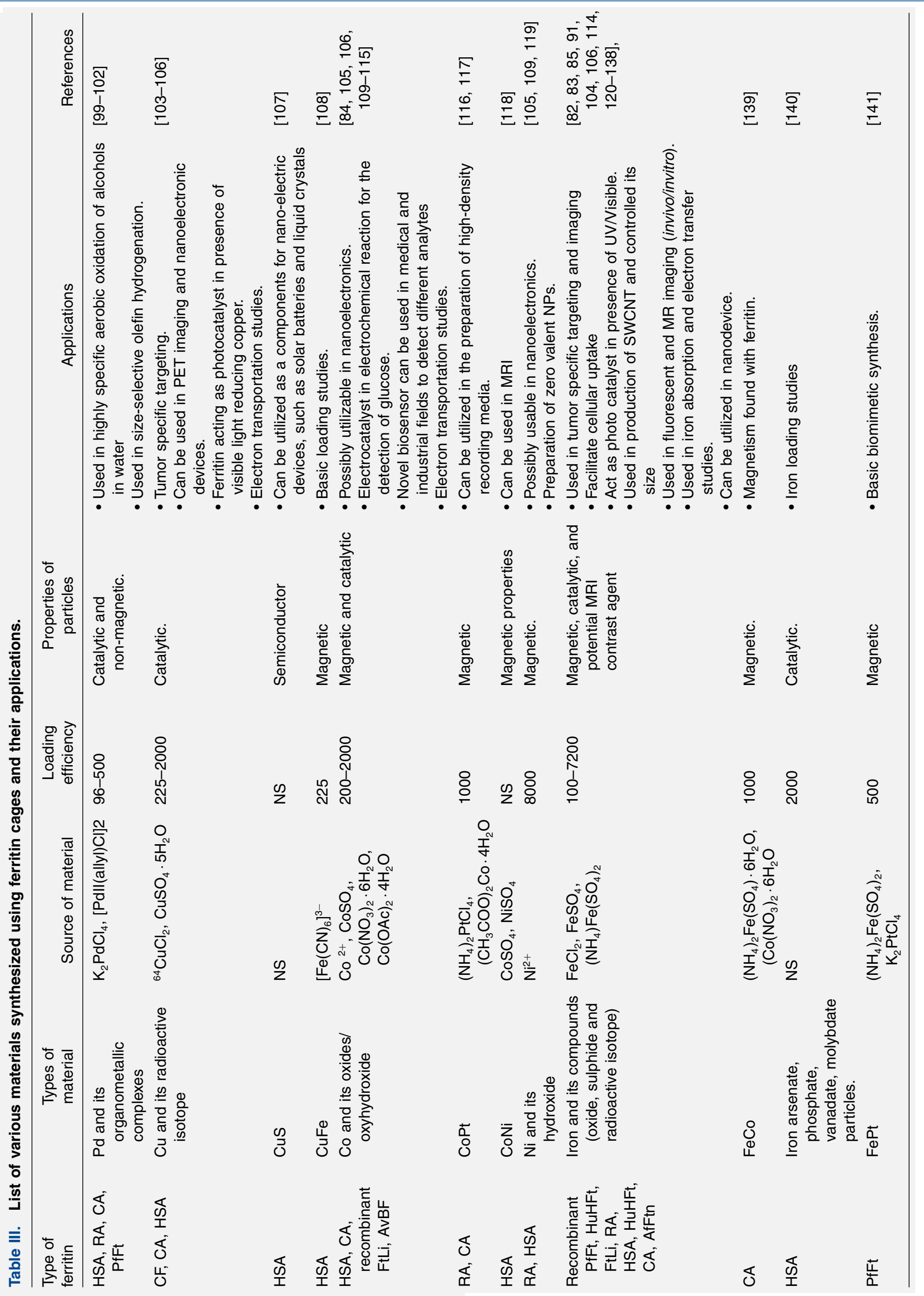




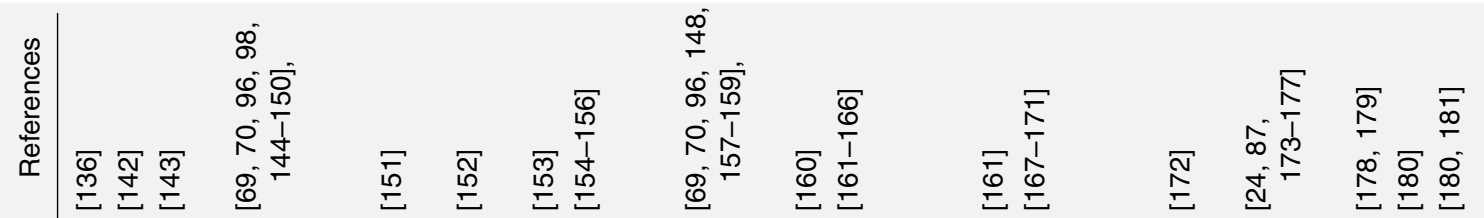

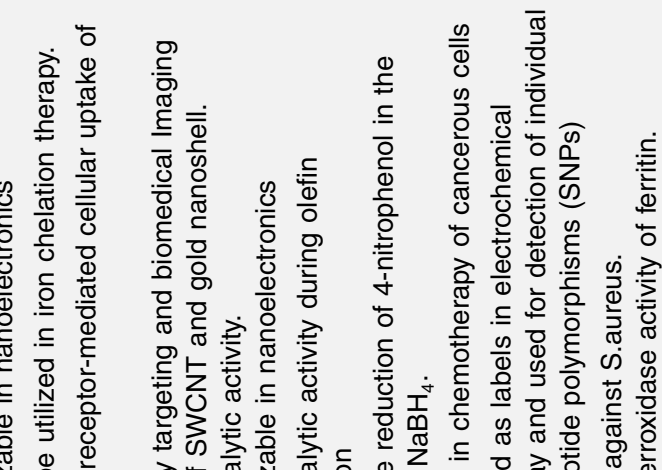

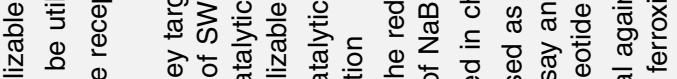

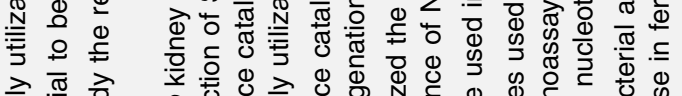

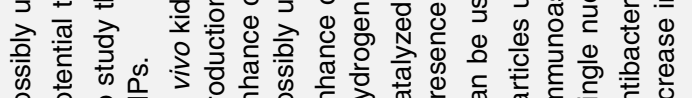

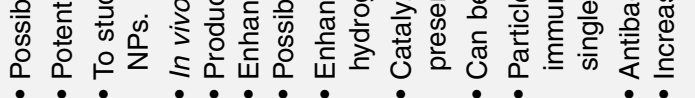

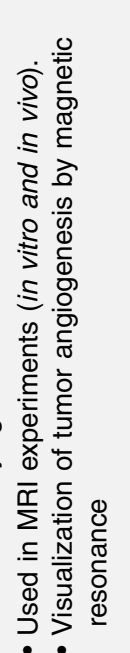

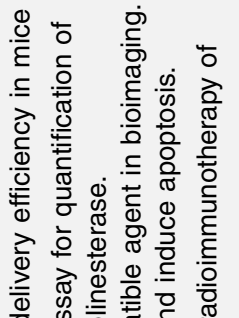

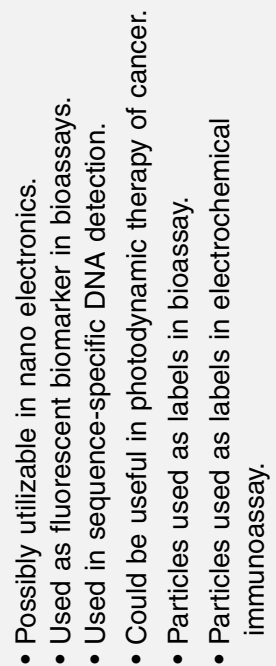

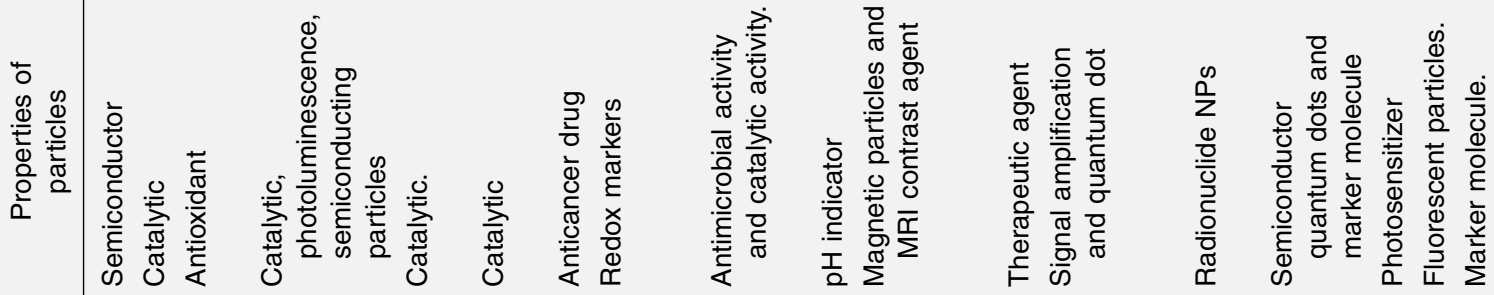

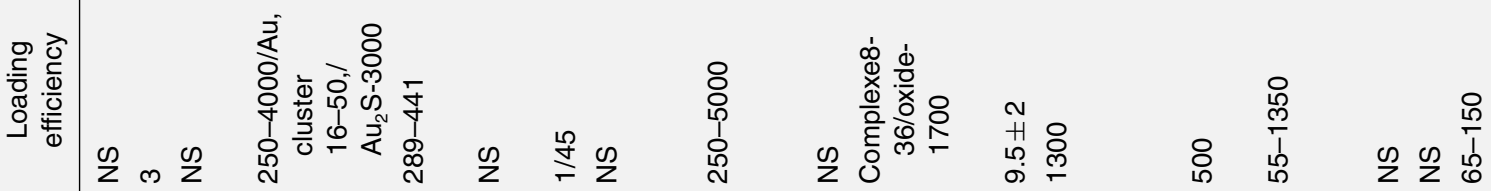

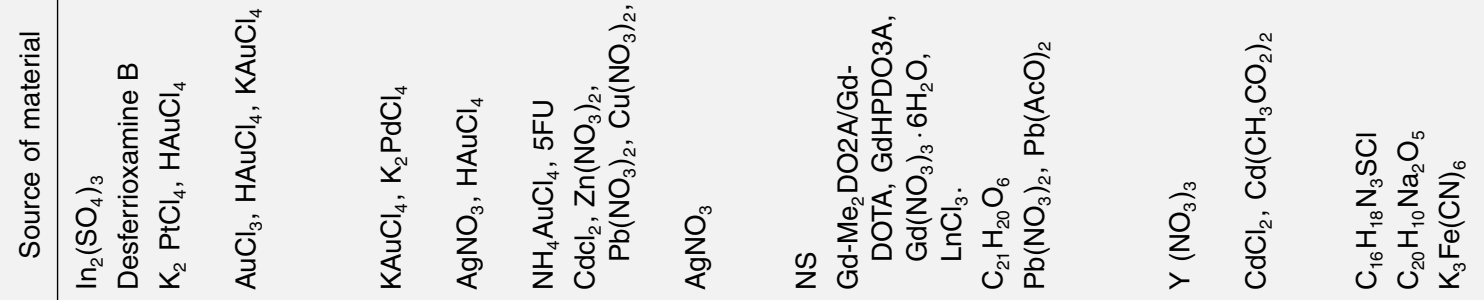

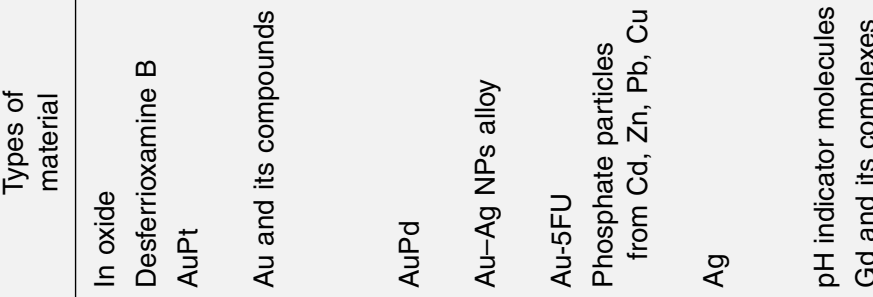

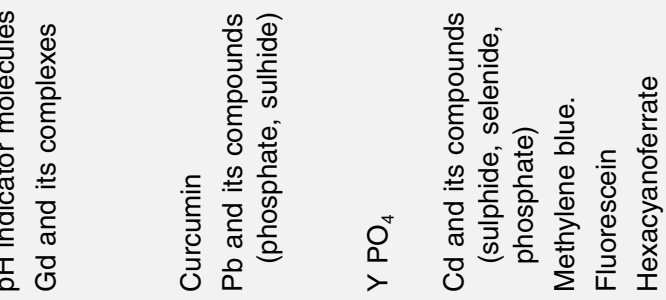

岂



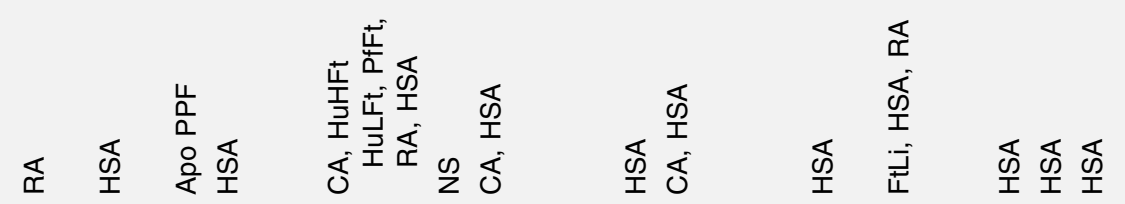




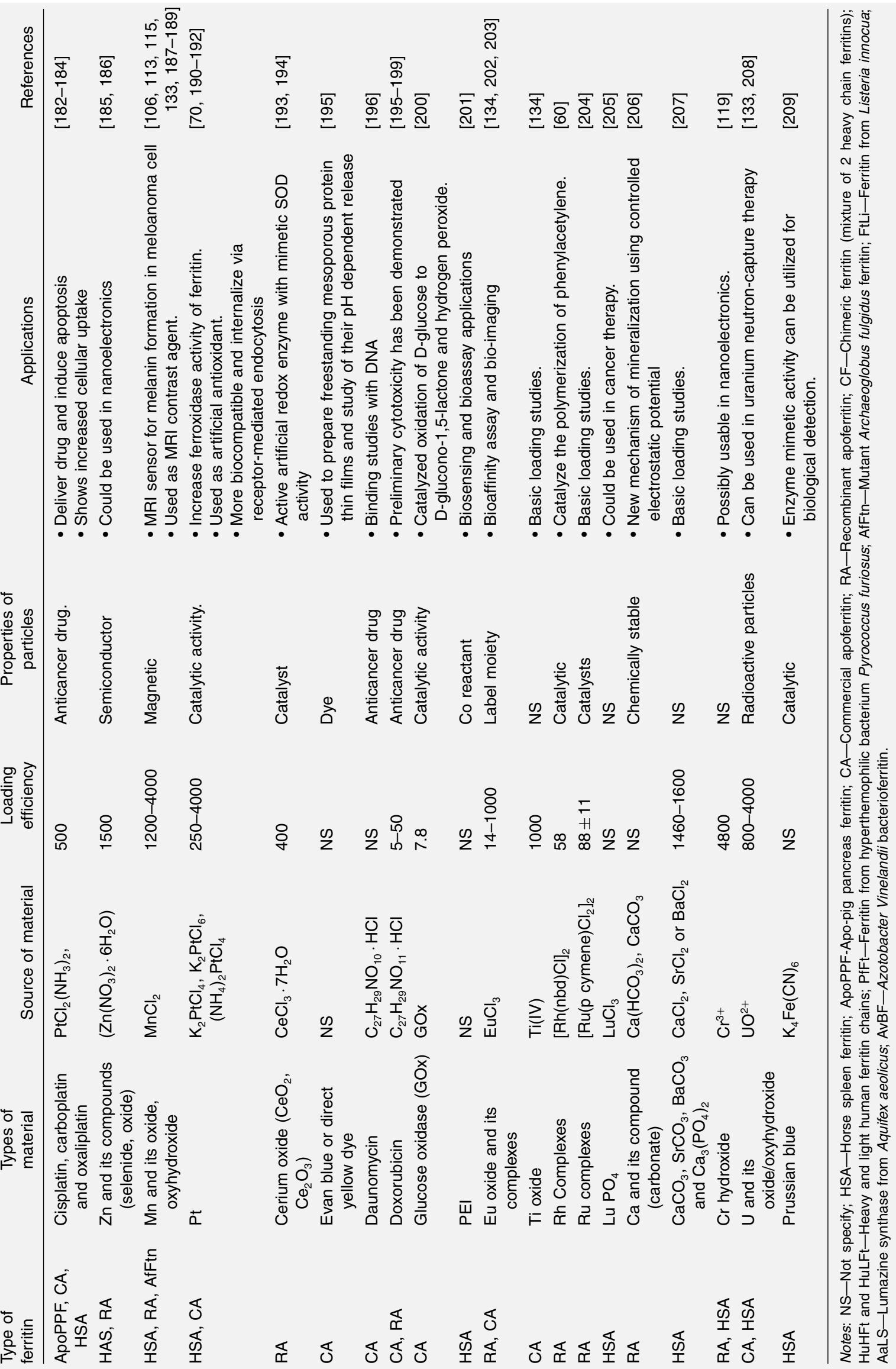


having gold-binding peptide and titanium-binding peptide at the $\mathrm{C}$ - and N-terminus, respectively that specifically catch gold NPs and deliver them to the silicon dioxide surface under specific conditions. ${ }^{98}$ List of various moieties encapsulated inside the ferritin protein cage is discussed in Table III.

\section{APPLICATIONS OF FERRITIN PROTEIN CAGES}

Ferritin nanocages have been widely used in various biological and biomedical applications as discussed below (Scheme 3).

\section{Tumor Therapy}

Apoferritin can encapsulate a variety of therapeutic agents, which can be utilized in different strategies for tumor treatment. Some of the strategies include:

\section{Neutron Capture Therapy}

Neutron capture therapy is a promising methodology for the treatment of cancer. Boron and uranium are the basic elements used in this technique. They are localized to the targeted tumor cell and irradiated with slow neutron, which leads to the disintegration of nuclei into smaller fragments along with ionizing particles that kill the cell. In early 90's, Hainfeld first described a method to deliver ${ }^{235} \mathrm{U}$ by encapsulating it in apoferritin cage which minimize the immune response and heavy metal toxicity. Antibody Fabfragments were chemically coupled to the protein cage for tumor specific targeting. The isotope was then fissioned by neutron beam that produced the required localized lethal radiation for the tumor therapy. ${ }^{208}$

\section{Radioimmunoimaging and Radioimmunotherapy}

Lutetium-177 is a radionuclide having a physical halflife of 6.7 days and other radiological properties such as emission of low energy beta particles and gamma radiation have been utilized for targeting small tumors for radioimmunoimaging and radioimmunotherapy of cancer. $^{210} \mathrm{~A}$ radionuclide nanoparticles (NPs) have been synthesized by conjugating apoferritin with lutetium phosphate $\left(\mathrm{LuPO}_{4}\right)$ or yttrium phosphate $\left(\mathrm{YPO}_{4}\right)$ and functionalized them with biotin. The pretargeting capabilities of these nanoparticle conjugates were studied using biotin-modified $\mathrm{LuPO}_{4}$ or $\mathrm{YPO}_{4}$-apoferritin with streptavidin-modified magnetic beads and in addition with the aid of streptavidin-modified fluorescein isothiocyanate (FITC) tracer. This method can be further exploited for the preparation of radioactive $\mathrm{LuPO}_{4}$ or $\mathrm{YPO}_{4}$

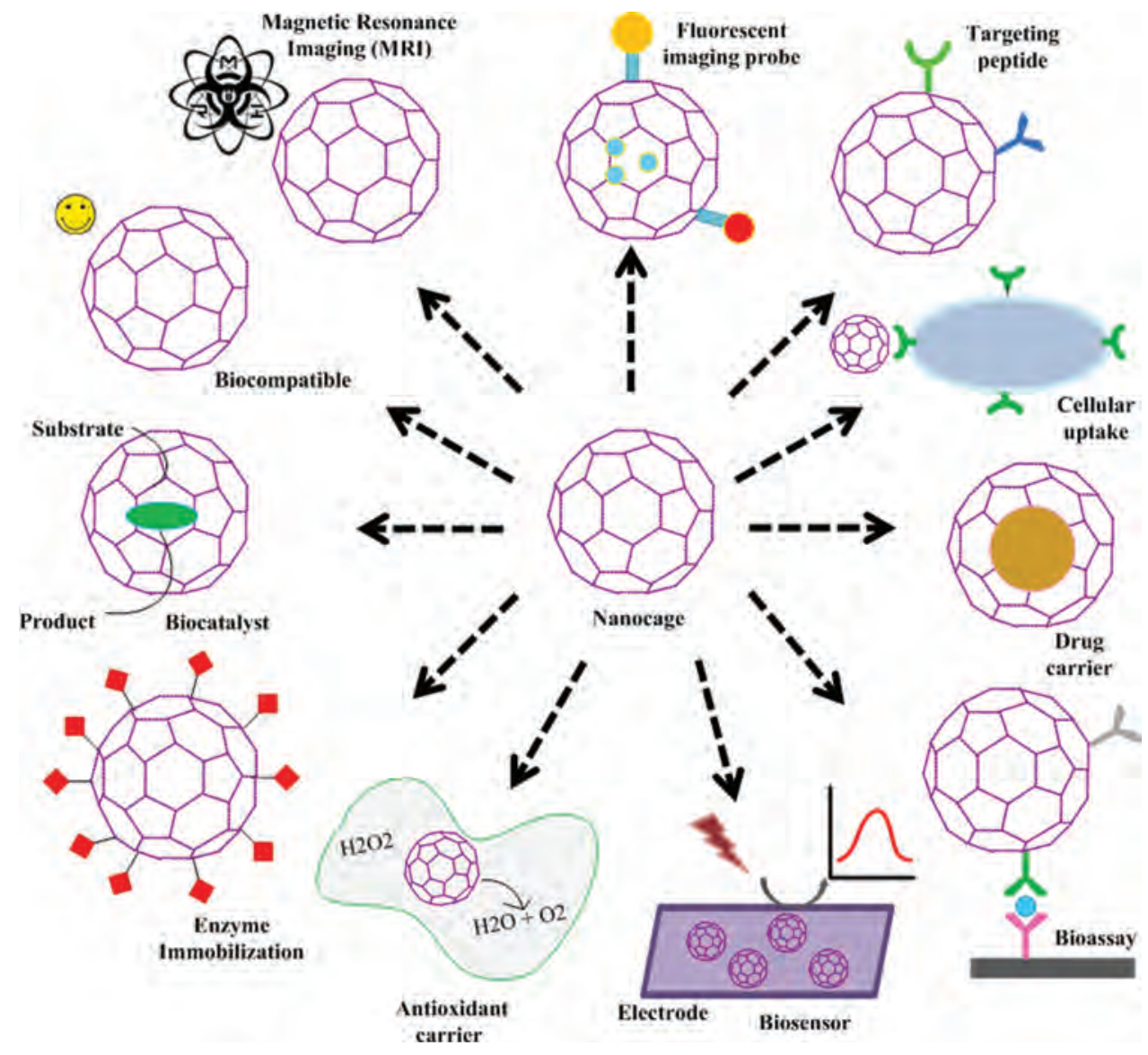

Scheme 3. Schematic representation of various applications of ferritin nanocages. 
conjugates that can be utilized in radioimmunotherapy of cancer. $^{172,205}$

\section{Photodynamic Therapy}

Photodynamic therapy (PDT) has emerged as an important tool in the field of tumor therapy and has been utilized for the treatment of both oncological (e.g., tumors and dysplasias) and non-oncological (e.g., age-related macular degeneration, localized infection and non-malignant skin conditions) applications. ${ }^{211}$ In this strategy, photosensitizing agents, light, and oxygen take part in photochemical reaction. A photosensitizing agent, methylene blue has been successfully encapsulated inside apoferritin cage, that can be internalized by the tumor cells and on irradiation with a light of suitable wavelength (i.e., $633 \mathrm{~nm}$ ) generates a cytotoxic agent, a singlet oxygen intracellularly for photodynamic therapy (PDT) which induced cytotoxic effects on the human breast adenocarcinoma cells (MCF-7). ${ }^{178,} 179$ Recently, a RGD4C-modified ferritin encapsulated with Zinc hexadecafluorophthalocyanine (ZnF16Pc), an effective photosensitizer showed a high tumor accumulation rate, less toxicity toward major organs and effective tumor inhibition on light irradiation by inducing phototoxicity in U87MG subcutaneous tumor models. ${ }^{212}$

\section{Anticancer Drug Carrier}

Toxicity and drug resistance of platinum based anticancer drug limited their use for cancer therapy. Apoferritin can be exploited as a drug delivery system to these platinum based drugs (cisplatin, carboplatin and oxaliplatin) to overcome these drawbacks and to enhance the cellular uptake of anticancer drugs. ${ }^{182}$ Cisplatin and carboplatin loaded apoferritin showed a primary toxicity against rat pheochromocytoma PC12 cells. ${ }^{183}$ Recently, a novel nanosized construct of cisplatin core-apo pig pancreas ferritin (NCC-PPF) has been developed and its anticancer activity on gastric cancer cells BGC823 (GCC) were studied. ${ }^{184}$

Daunomycin (anticancer drug) used for the treatment of acute myeloid leukemia and lymphocytic leukemia have been successfully encapsulated into apoferritin which is modified by incorporating a negatively charged polypeptide poly-L aspartic acid (PLAA) to improve their drug holding capacity. ${ }^{196}$ Similarly, apoferritin has been utilized for the encapsulation of anticancer drug doxorubicin. ${ }^{197,} 198$ A simple and easy method for preparation of thin mesoporous protein films has been developed for efficient loading and releasing of dye or doxorubicin by controlling the $\mathrm{pH}$. It loaded at lower $\mathrm{pH}$ and released the drug at higher $\mathrm{pH}$ than the isoelectric point of protein. ${ }^{195}$

The differential effect of near-infrared apoferritin- $\mathrm{PbS}$ $(\mathrm{AFt}-\mathrm{PbS})$ nanocomposites on cell cycle progression in normal and cancerous human cells has been recently reported. The nanocomposite did not alter the cell cycle in normal cell at concentration up to $1 \mathrm{mg} \mathrm{mL}^{-1}$ whereas in human breast cancer cell line it triggered apoptosis at concentration $>0.2 \mathrm{mg} \mathrm{mL}^{-1}$. These nanocomposites entered the cell through endocytosis and further could be used for the in vivo imaging studies. ${ }^{170}$ Another anticancer compound Ru complex has also been successfully immobilized to the ferritin cages by His residue present on the ferritin surface. $^{204}$

A bio-inspired nanoconstruct have recently been developed using an apoferritin-gold nanoconstruct loaded with anticancer drug 5-fluorouracil (5-FU) that exhibited a high selectivity towards cancerous cells and also increased the cellular uptake of 5-FU via receptormediated endocytosis. ${ }^{153}$ Moreover, a genetically modified ferritin (RFRTs) nanocages having a tumor targeting peptide Cys-Asp-Cys-Arg-Gly-Asp-Cys-Phe-Cys (RGD4C) attached on its surface has been used for the delivery of anticancer drug doxorubicin as shown in Figure 2. Such nanoconstruct showed high drug loading efficiency in presence of $\mathrm{Cu}(\mathrm{II})$ as a helper agent. This nanoconstruct have improved tumor suppression ability and reduced cardiotoxicity, when studied on U87MG subcutaneous tumor models. $^{199}$

\section{Other Therapeutic Applications}

Iron is one of the essential elements for all the living beings, but if present in excess becomes toxic. Human body is incapable to remove this excess iron, which leads to their accumulation in the liver and other organs leading to serious health complications and eventually death. ${ }^{213}$ To remove this excess of iron, Desferrioxamine B (DFO) drug produced by Streptomyces pylosus is used for iron chelation therapy by encapsulating it inside the apoferritin cage, which upon further reaction with Fe III gives rise to encapsulated [DFOFe] complex within the apoferritin. ${ }^{142}$

This nanocontainer can also be utilized for the treatment of other infectious disease. As in a newly developed strategy in which silver (I) ions were loaded into apoferritin to function as an antimicrobial agent. ${ }^{157}$ Recently, a novel theranostic agent has been constructed utilizing the apoferritin cage to simultaneously deliver the therapeutic agent (curcumin) and imaging agent (GdHPDO3A) to hepatocyte in mice. This nanoconstruct can be used to prevent hepatocellular damage in the thioacetamide-induced hepatitis and can simultaneously evaluate the drug delivery efficiency via Magnetic resonance imaging (MRI), as apoferritin cage is efficiently taken up by hepatocyte scavenger receptor class A type 5 from blood via the ferritin transporting route. ${ }^{161}$

\section{Tumor Imaging}

In order to improve the quality and accuracy of disease management, a fused technique has been developed by coupling the multiple imaging techniques as shown in Figure 3. Near-infrared fluorescence (NIRF) imaging and positron emission tomography (PET) are combined in order to minimize the chances of misdiagnosis and used for in vivo imaging. A chimeric ferritin nanocage has been developed by introducing RGD4C and Cy5.5 on 

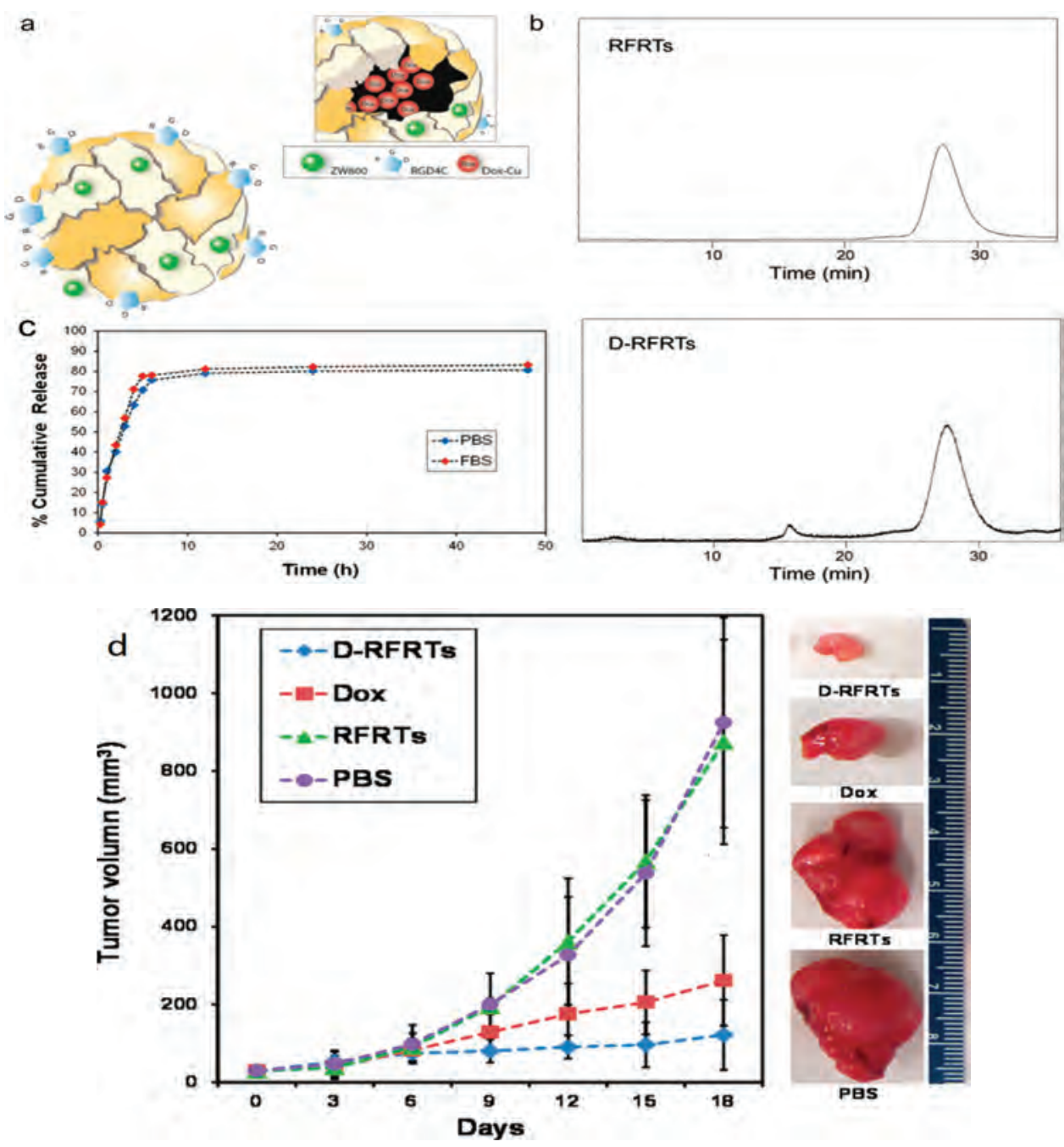

Figure 2. (a) Schematic illustration of D-RFRTs. Dox was precomplexed with Cu, and then encapsulated into RFRTs. (b) Gelfiltration chromatography analysis of RFRTs and D-RFRTs. The same peak at around 27.4 min was observed for both RFRTs and D-RFRTs. (c) Cumulative drug release curves of D-RFRTs in PBS (pH 7.4) and FBS. (d) Therapy studies performed on U87MG tumor-bearing nude mice ( $n=5$ /group). On day 18, significant difference in tumor growth was found between D-RFRT treated mice and those treated with PBS, RFRTs and free Dox $(P<0.05)$. Eighteen days after the onset of the treatment, a TGI rate of $\mathbf{8 9 . 6 \%}$ was observed for D-RFRTs, in comparison to that of $74.0 \%$ for free Dox. Reprinted with permission from [199], Z. Zhen, et al., RGD-modified apoferritin nanoparticles for efficient drug delivery to tumors. ACS Nano 7, 4830 (2013). @ 2013, American Chemical Society.

the exterior surfaces of hybrid ferritin cage via genetic and chemical means. These nanocages loaded with ${ }^{64} \mathrm{Cu}$ onto heavy chain of ferritins have a potential as multifunctional loading and multimodality imaging probes. This hybrid nanoprobe has both PET and NIRF functionalities for tumor imaging in conjugation to integrin specific targeting, when injected intravenously into tumorbearing mice. ${ }^{103}$ Similarly, it has been demonstrated that the engineered human ferritin protein cages conjugated with either fluorescent Cy5.5 molecule or encapsulating magnetite nanoparticles, can serve as a nano-platform to image vascular inflammation in vivo. They can be successfully taken up by the macrophages in murine atherosclerotic carotid arteries and thus served as a novel platform as MR or Near-infrared (NIR) contrast agents for detecting macrophage infiltration within atherosclerotic plaques to detect high-risk atherosclerotic plaques. ${ }^{130}$

In a recent study, a multifunctional ferritin cage-based nanostructure has been developed for the fluorescence and MR imaging and for detection of $\alpha_{v} \beta_{3}$ integrin upregulation in tumor cells by attaching green fluorescent protein (GFP) and Arg-Gly-Asp (RGD) peptide on the exterior surface of the ferritin cages and ferrimagnetic iron oxide nanoparticles to the interior cavity. ${ }^{132}$ Paired gold clusters have been synthesized within the interior cavity of apoferritin cage with tunable fluorescent emissions, suggesting the occurrence of fluorescence resonance energy transfer (FRET) effects between the clusters and use of these novel biomolecule-metal complexes for in vivo kidney targeting and biomedical imaging. ${ }^{145}$ 


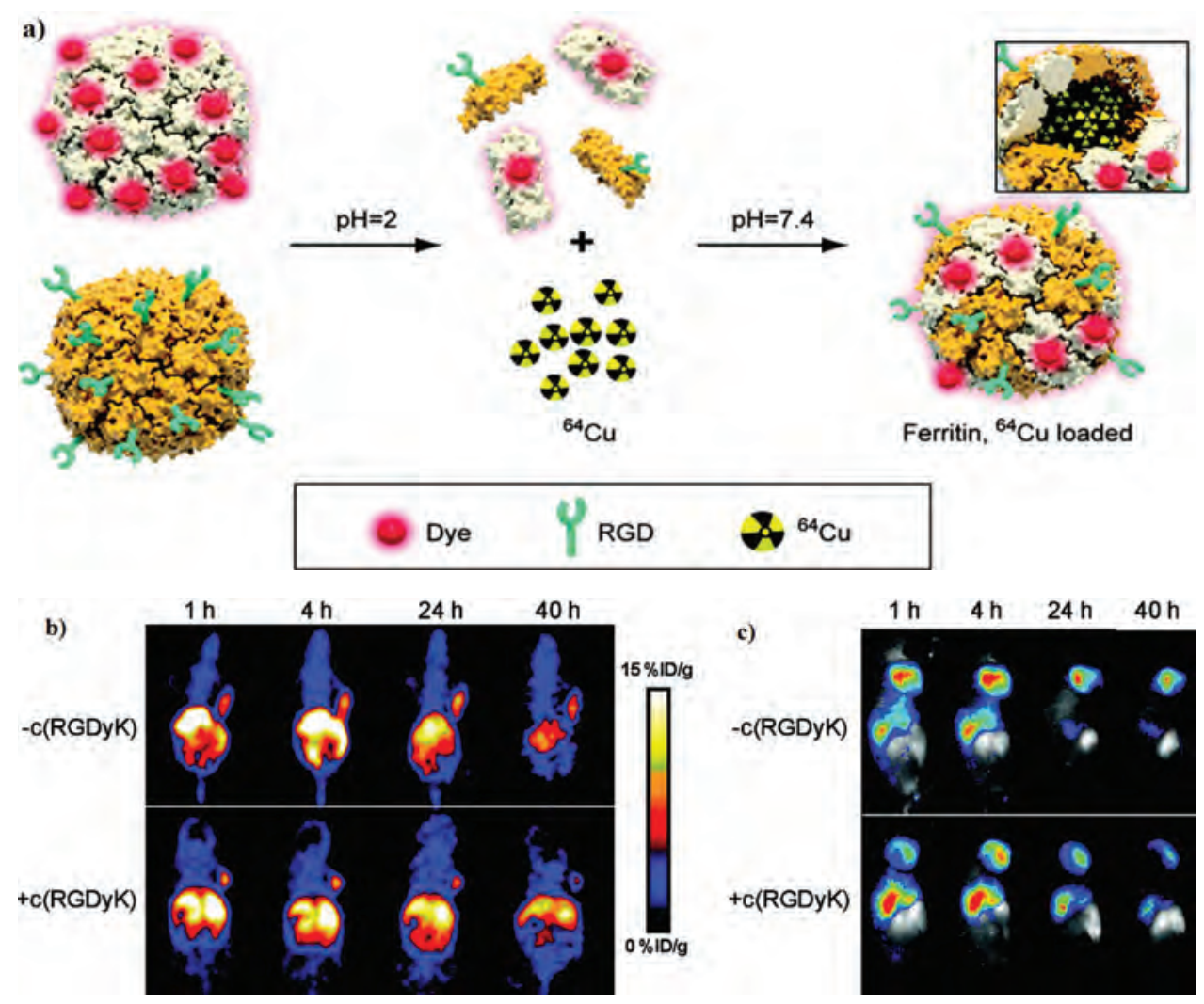

Figure 3. (a) Schematic illustration of the process of triple-loading. First, we introduced RGD4C and Cy5.5 onto the surfaces of two sets of ferritins, via genetic and chemical means. These two ferritins were then mixed and broken down into subunits at $\mathrm{pH}=2$ and incubated with ${ }^{64} \mathrm{CuCl}_{2}$ to achieve radiolabeling. The $\mathrm{pH}$ was then adjusted back to 7.4 to facilitate the reformation of nanostructures. The reconstituted chimeric ferritin nanocages have both RGD4C and Cy5.5 on their surfaces and ${ }^{64} \mathrm{Cu}$ loaded in their cavities. In vivo (b) PET and (c) NIRF images after the administration of ferritin probes. In the comparison group, a blocking dose of $c$ (RGDyK) was injected $30 \mathrm{~min}$ prior to the ferritin probe administration. Reprinted with permission from [103], $X$. Lin, et al., Chimeric ferritin nanocages for multiple function loading and multimodal imaging. Nano Lett. 11, 814 (2011). @ 2011, American Chemical Society.

In a similar way, gadolinium 1,4,7-tris(carboxymethyl)10-(2'-hydroxypropyl)-1,4,7,10-tetraazacyclododecane (GdHP-DO3A) loaded apoferritin probe has been used for MR visualization of tumor blood vessels (tumor angiogenesis) in a mouse model by utilizing biotin-streptavidin affinity and targeting neural cell adhesion molecules. ${ }^{165}$ Recently, a artificial luminescent protein has been developed by encapsulating a strongly luminescent $\mathrm{Eu}^{3+}$ complex, $N, N, N 1$, $N 1$-[40-(1-naphthyl)-2,20:60,200-terpyridine-6,60 0-diyl] bis(methylenenitrilo) tetrakis(acetic acid) (NTTA-Eu ${ }^{3+}$ ) into cavity of apoferritin which act as a bioprobe for time-gated luminescence bioimaging. This bioprobe can be used to understand the distribution and function of apoferritin inside complex living systems. ${ }^{203}$

\section{Tumor Targeting}

Protein based NP systems are the promising tool for the targeted delivery of imaging and therapeutic agents. The advantage of these NPs over other conventional systems lies in their ease to undergo cage modification and extends to the wide possibility for loading a variety of moieties for diagnostic and therapeutic purposes. These functional moieties include targeting agents that can effectively recognize the receptor, over expressed by specific cells and tissues.

Magnetic nanoparticles loaded apoferritin conjugated with fluorescently labeled RGD-4C peptide can be taken up by macrophages more efficiently due to their specific affinity with amelanotic melanoma cells and THP-1 monocyte cells, which are known to overexpress integrin $\alpha_{v} \beta_{3}{ }^{214}$ Similarly, a multifunctional NPs have been formulated for cell specific targeting by encapsulating iron oxide (magnetite) NPs within the interior cavity of genetically engineered human $\mathrm{H}$-chain ferritin ( $\mathrm{HFn}$ ) and a fluorescent dye, Fluorescein- 5-maleimide along with cell specific targeting peptide, RGD-4C as shown in Figure 4. RGD-4C were attached on its exterior surface which enabled specific binding to $\alpha_{v} \beta_{3}$ integrins upregulated on tumor vasculature and $\mathrm{C} 32$ melanoma cells in vitro. ${ }^{122}$

Recently, multifunctional nanoparticles have been developed by genetically and chemically modifying the heavy chain of the human protein ferritin (HFt), stabilizing and masking them with polyethylene glycol (PEG) molecules, 
TEM


DLS
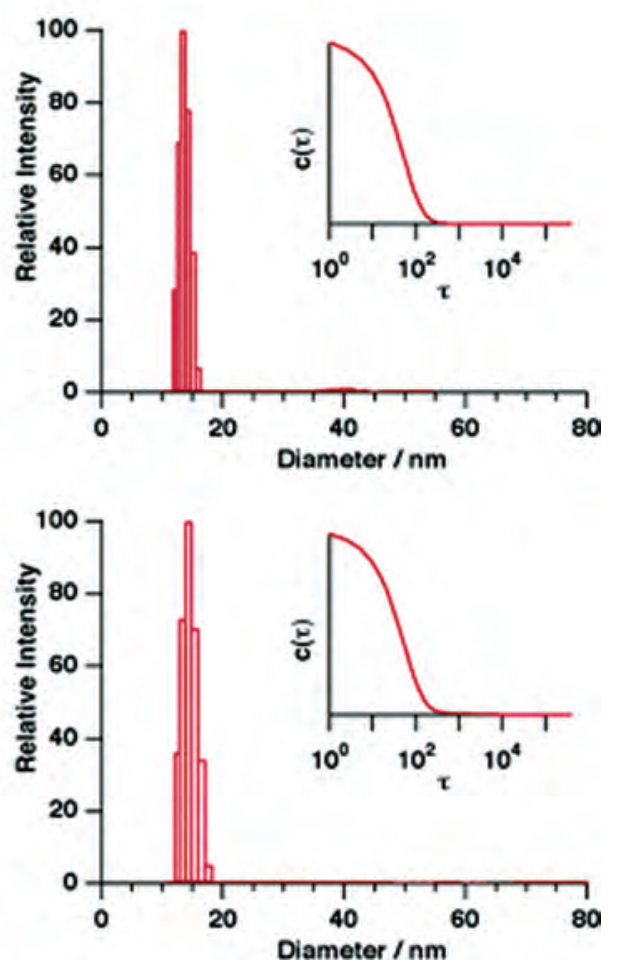

Figure 4. TEM images (left) and DLS analysis (right; insets are the corresponding correlation functions) of empty HFn and RGD4C-Fn. Both HFn and RGD4C-Fn show 12-14 nm in diameter. Reprinted with permission from [122], M. Uchida, et al., Targeting of cancer cells with ferrimagnetic ferritin cage nanoparticles. J. Am. Chem. Soc. 128, 16629 (2006). ( 2006, American Chemical Society.

rhodamine fluorophores and magnetic resonance imaging contrasting agents for selective melanoma-targeting both in vitro and in vivo. These constructs were specifically targeted to the melanoma cell by attaching selective targeting moiety, such as $\alpha$-melanocyte stimulating hormone $(\alpha$-MSH) peptide on the surface of protein, which binds to the receptors expressed only by melanoma cells and to some extend by melanocytes. In this study, there was considerable reduction in non-specific recognition and uptake by the reticuloendothelial and mononuclear phagocytic systems as HFt-MSH-PEG were easily recognized and taken by the melanoma cells and not by other human cancer cells or mouse tissues (expect by dedicated phagocytes). ${ }^{128}$

\section{Cellular Uptake}

Ferritin in natural conditions enters into cell though receptor mediated endocytosis due to the presence of endogenous ferritin receptors and for site specific targeting of ferritin their exterior surface could be modified. The receptor for ferritin varies with the type of cell and tissue and on their developmental stages. The ferritin receptors were found on different types of cells including lymphocytes, ${ }^{215}$ placental microvilli, ${ }^{216}$ and erythroid precursors. ${ }^{217}$ These are also found on various cell lines, such as giant HeLa cells, ${ }^{218} \mathrm{~K} 562$ cells, ${ }^{219}$ and human intestinal carcinoma
Caco-2 cells, which can even internalize plant ferritin. ${ }^{220}$ In absence of transferrin receptors, ferritin L-chain receptors (scara 5) have been found on developing kidney for the iron uptake. ${ }^{221}$

It has been previously reported that ferritin bind to the membrane of HeLa cells and is internalized through ferritin receptors via endocytosis. ${ }^{218}$ For example, in embryo Tim2 is reported as the receptor for H-ferritin, ${ }^{222}$ whereas in many other cell lines such as HeLa cells and immunogenic cells such as mitogen-activated T- and B-cells, cellular uptake is facilitated via human transferrin receptor-1 (TfR1). ${ }^{223}$

Apoferritin nanocage can act as a natural and biocompatible carrier for the cellular delivery of bioactive molecules through receptor-mediated endocytosis and provide a non-destructive (to the cell membrane) and switchable control of their cellular uptake by inhibition of endocytosis which make them a highly flexible and practical nanocarrier for drug delivery. The control of the delivery system was tested on human intestinal epithelial Caco- 2 cells, as they exhibit ferritin receptors. ${ }^{143}$

\section{Bioassays}

In the modern era of nanotechnology, use of nanoparticles has emerged as an important tool in the field of biomedical applications because of their simplicity, high surface area 
and unique physiochemical properties at the nanoscale. They have been widely utilized in development of highly sensitive bioassays for biomolecular diagnosis. Apoferritin in combination with other metal NPs have been extensively studied for molecular diagnosis, bioimaging, targeted drug delivery and therapeutics.

A fluorescence marker (fluorescein anion) and a redox marker [hexacyanoferrate (III)] loaded apoferritin has been synthesized that can be used as bioassay labels for

(A)

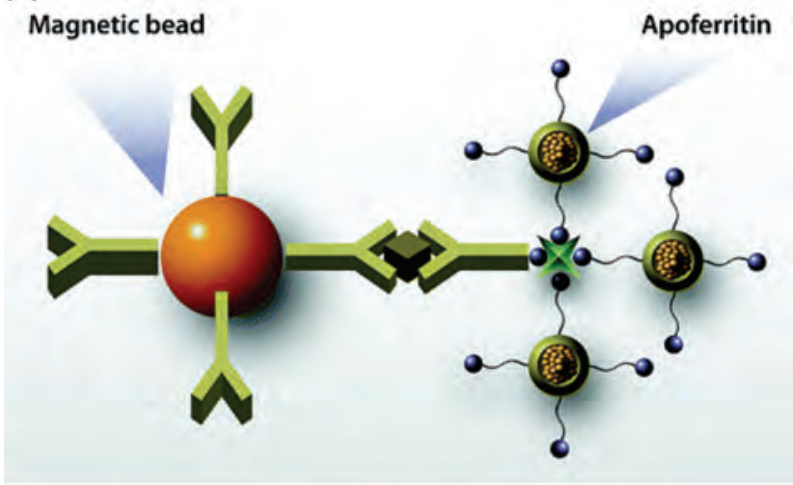

(B)

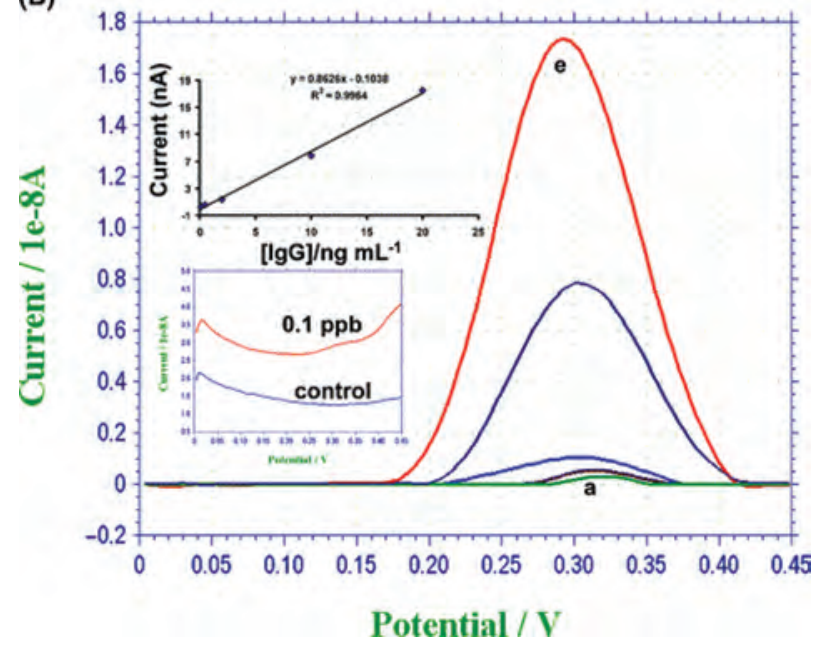

Figure 5. (A) Magnetic beads and electrochemical sandwich immunoassay protocol based on biotin-functionalized hexacyanoferrate MLAN labels. (B) Typical square wave voltammograms of electrochemical immunoassay with increasing concentration of the IgG (from a to e, 0.1, 0.5, 2, 10, and $20 \mathrm{ng} \mathrm{mL}^{-1} \mathrm{IgG}$, respectively). A baseline correction of the resulting voltammogram was performed using the "linear baseline correction" mode of the $\mathrm{CHI} 660$ ( $\mathrm{CH}$ Instruments) software. Also shown (insets), (top) the resulting calibration plot and (bottom) the square wave voltammograms (without baseline correction) of 0.1 and $0 \mathrm{ng} \mathrm{mL}^{-1}$ (control) IgG. After the sandwich hybridization assay, the magnetic beadhexacyanoferrate loaded apoferritin hybrid was dispersed in $50 \mu \mathrm{L}$ of $0.1 \mathrm{M} \mathrm{HCl} / \mathrm{KCl}$ to release the captured hexacyanoferrate. Following a magnetic separation, the solution was transferred to a SPE surface for SWV scanning. Reprinted with permission from [180], G. Liu, et al., Versatile apoferritin nanoparticle labels for assay of protein. Anal. Chem. 78, 7423 (2006). ๑ 2006, American Chemical Society. microscopic fluorescence immunoassay and electrochemical immunoassay, respectively as shown in Figure 5. Its detection limits were estimated to be of $0.06(0.39 \mathrm{pM})$ and $0.08 \mathrm{ng} \mathrm{mL} \mathrm{m}^{-1}(0.52 \mathrm{pM}) \mathrm{IgG}$ with fluorescein and hexacyanoferrate, respectively. ${ }^{180,181}$ The biologically produced functionalized NPs were also used as labeling agents in bioaffinity assay. In this study, Eu3+ ions were used as labeling agent and were loaded inside the ferritin, while a binding moiety i.e., single chain Fv fragment $(\mathrm{scFv})$ of an antibody was attached on its surface in order to aid their specific binding to the thyroid stimulating hormone (TSH). ${ }^{202}$

A new highly sensitive and selective magnetic particle (MP)-based electrochemical immunoassay has been demonstrated, having a detection limit of $0.01 \mathrm{ng} / \mathrm{mL}$ using carbon nanospheres (NS) and lead phosphate loaded protein cage nanoparticles (PCN) for signal amplification. This system has been used to analyze the phosphorylated protein human phospho-p5315, a potential biomarker of gamma-radiation exposure. ${ }^{167}$

In a similar way, a co-reactant based highly sensitive electro chemiluminescence (ECL) immunoassay approach has been devised based on PEI loaded apoferritin NPs, probes for the specific quantification of human chorionic gonadotrophin (HCG) by enhancing the ECL of ruthenium (II) tris $\left(2,2^{\prime}\right.$-bipyridyl) $\left(\mathrm{Ru}(\mathrm{bpy})_{2}^{+3}\right){ }^{201}$ Moreover, for rapid, sensitive, selective and inexpensive quantification of organophosphorylated acetylcholinesterase (OP-AChE), an exposure biomarker of organophosphate based pesticides. A new sandwich type electrochemical immunoassay has been developed using apoferritin templated lead phosphate label for quantification of OP-AChE, having a detection limit of $0.02 \mathrm{nM} .^{168}$ These new apoferritin based nanoparticle labels hold great promise in the field of biomolecule detection and in enhancing the sensitivity of various other bioassays.

\section{Biosensors}

The metal encapsulated apoferritin NPs can be used in variety of nanodevices, such as single electron transistor, catalysis and floating gate memory. In similar way, semiconductor NPs such as CdSe, ZnSe, and CdS encapsulated apoferritin can be used as quantum dots and photofluorescence markers. ZnSe is a $n$-type semiconductor that could be used as fluorescent labels for biological applications as their fluorescent light does not quench easily.

Ferritin molecules have redox property which remains unchangeable until their electrochemical surrounding is fixed. $^{224}$ In recent years, protein electrochemistry has emerged as an interesting area in the development of biosensors and bioreactors. Various electron transfer reaction studies of ferritin have been conducted, such as electron transfer of ferritin on bare gold electrode. ${ }^{225}$ The electrochemical behavior of ferritin adsorbed on indium-tin oxide (ITO) glass and single wall nanotubes (SWNT)/ferritin composite on glassy carbon (GC) 
disk electrode had been studied for nanoelectronic applications. ${ }^{226,227}$ Moreover, electrochemical studies on ferritin immobilized onto a self-assembled monolayermodified gold electrode have been already reported. ${ }^{228}$ The direct electron transfer of ferritin in Dihexadecyl phosphate (DHP) on Au film electrode was also evaluated. ${ }^{229}$

A ferritin/DNA complex was successfully constructed by chemically attaching maleimide modified DNA (M-DNA) to the exterior surface of a ferritin mutant protein, which can be sterically attached to the complementary DNA-functionalized GNPs. This complex can be utilized in photo electrochemical biosensor fabrication as it can serve as a mediator between the DNA/RNA responsible for disease and dye-labeled photo reporter probe. ${ }^{137}$

A highly sensitive electrochemical approach have been reported having a linear range from $2.0 \times 10^{-16}$ to $1.0 \times$ $10^{-14} \mathrm{M}$ and the detection limit was $5.1 \times 10^{-17} \mathrm{M}$ under optimum condition, based on signal dual-amplification with $\mathrm{Au}$ NPs and marker-loaded apoferritin NPs for the sequence-specific DNA detection. The concentration of target DNA is quantified by electrochemical stripping analysis of the electroactive cadmium markers released from apoferritin NPs in acidic buffers. This proposed DNA biosensor has high sensitivity, good reproducibility and selectivity even against two-base mismatched DNA. ${ }^{176}$ Recently, a direct electron transfer has been investigated between cobalt NPs loaded apoferritin and a glassy carbon electrode in thin film of dihexadecyl phosphate (DHP) by cyclic voltammetry (CV) in order to design a biosensing device that can be used in detection of various chemical and biological analytes. ${ }^{112}$

In addition to this, an electrochemical approach has been developed using metal phosphate nanoparticles loaded monobase-conjugated apoferritin probe for the detection of individual single nucleotide polymorphisms (SNPs). The biotinylated DNA probes get hybridized with mutant and complementary DNA and the duplex DNA helix form were captured on the surface magnetic beads by biotinstreptavidin based affinity binding. Signals were generated and detected by electrochemical stripping analyses, when the probes get coupled to the mutant sites of formed duplex DNA by DNA polymerase, as each mutation captures different nucleotide-conjugated apoferritin probe and generates distinct potential voltammogram peaks relative to mismatch. ${ }^{156}$

An array of charged storage nodes in floating gate memory had been developed using ferritin encapsulated NPs. ${ }^{230}$ Apoferritin loaded with $\mathrm{Ni}$ atoms catalyzed the fabrication of high quality polycrystalline silicon $(\mathrm{Si})$ thin film from an amorphous Si thin film. ${ }^{231}$

In general, electrochemical biosensors utilize the potentiometric and amperometric transducers that convert the biosensing information into the measurable signal. Recently, apoferritin encapsulated gold nanoparticles have been utilized to perform electrochemical DNA biosensing having a sensitivity up to 51 aM. ${ }^{176}$ Apoferritin

bionanomaterial also enhances electron transfer reactions of hemoglobin in a wide $\mathrm{pH}$ range. Since, the $\mathrm{Hb}$ exhibit catalytic activity toward $\mathrm{H}_{2} \mathrm{O}_{2}$, the construct can be used for the development of $\mathrm{H}_{2} \mathrm{O}_{2}$ biosensor. ${ }^{232}$

\section{Biocatalyst}

Apoferritin loaded nanoparticles also found their role in catalyzing various chemical reactions. As shown in Figure 6, polymerization of phenylacetylene has been catalyzed by the Rhodium (Rh(nbd)) complexes immobilized within the discrete space of apoferritin that can be useful in investigating the behavior of a single polymer chain isolated within a nano-sized space. ${ }^{60}$ Similarly, they have also demonstrated that the ferrocenes and $\mathrm{Pd}($ allyl) complexes were immobilized on the interior surface of apoferritin. The Pd(allyl) complexes immobilized by forming a thiolbridged dinuclear complexes and catalyzed the redox and Suzuki coupling reactions. ${ }^{101,233}$

a)

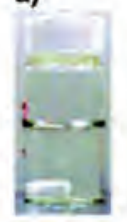

b)
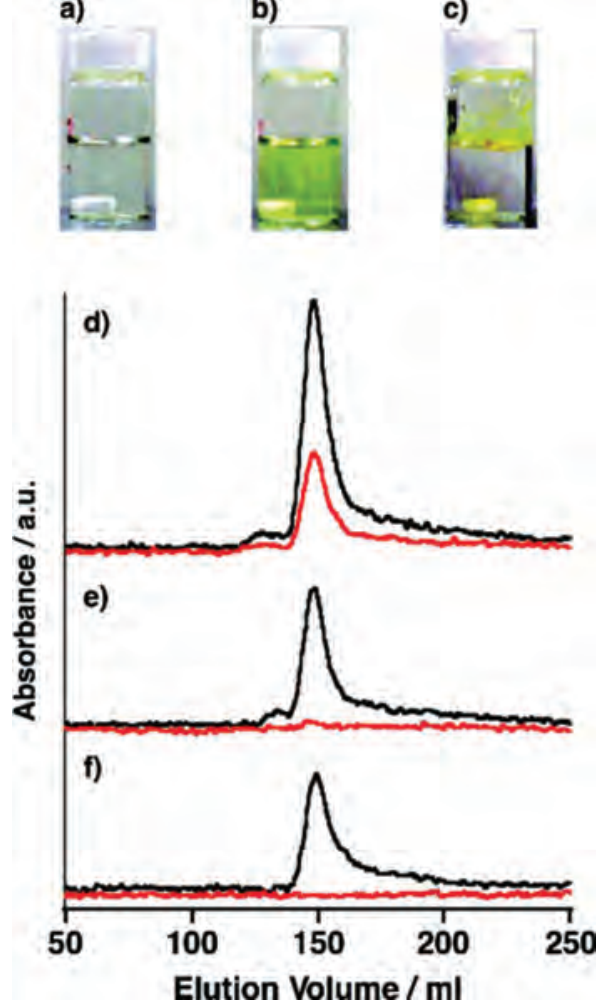

c)

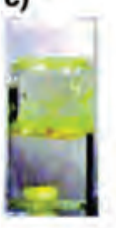

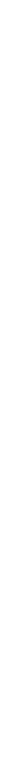

Figure 6. Polymerization of phenylacetylene catalyzed by $\mathrm{Rh}(\mathrm{nbd}) \cdot$ apo-Fr. (a) Solution of $\mathrm{Rh}(\mathrm{nbd}) \cdot$ apo-Fr prior to addition of phenylacetylene (b) Reaction mixture of $\mathrm{Rh}(\mathrm{nbd}) \cdot$ apo-Fr and phenylacetylene after stirring for $3 \mathrm{~h}$ at $25{ }^{\circ} \mathrm{C}$. (c) Reaction mixture of $[\mathrm{Rh}(\mathrm{nbd}) \mathrm{Cl}]_{2}$ and phenylacetylene under the same conditions. (d)-(f) Elution profiles from size-exclusion chromatography of (d) $\mathrm{Rh}(\mathrm{nbd}) \cdot$ apo-Fr after the reaction, (e) $\mathrm{Rh}(\mathrm{nbd}) \cdot \mathrm{apo}-\mathrm{Fr}$, and (f) apo-Fr. Elution was monitored at both $280 \mathrm{~nm}$ (black line) and $383 \mathrm{~nm}$ (red line). Reprinted with permission from [60], S. Abe, et al., Polymerization of phenylacetylene by rhodium complexes within a discrete space of apo-ferritin. J. Am. Chem. Soc. 131, 6959 (2009). @ 2009, American Chemical Society. 
In a similar way, Pd has been encapsulated within the core of a hyperthermophilic ferritin cages (from pyrococcus furiosus) to form a hybrid catalysts that can be used for highly specific aerobic oxidation of alcohols in water. ${ }^{99}$ In addition to this, it has been demonstrated that the apoferritin encapsulated Pd nanocluster catalyzes the size-selective olefin hydrogenation. ${ }^{100}$

The $\mathrm{Fe}(\mathrm{O}) \mathrm{OH}-m i n e r a l i z e d$ iron storage protein ferritin was used to catalyze the photoreduction of aqueous $\mathrm{Cr}$-(VI) species to $\mathrm{Cr}(\mathrm{III}), \mathrm{Cu}(\mathrm{II})$ to form a stable, air sensitive, colloidal dispersion of $\mathrm{Cu}(0)$ and reduction of cytochrome $\mathrm{c}$ and viologens as well as the oxidation of carboxylic acids, thiol compounds, and sulfite. Ferritin act as photocatalyst in presence of UV/visible light and can be utilized for future photocatalytic applications, such as in environmental remediation chemistry. ${ }^{125,126,104}$ These NPs also acts as a catalyst for the growth of singlewalled carbon nanotubes. ${ }^{124}$ Similarly, it has been reported that $1-2 \mathrm{~nm}$ and $3-5 \mathrm{~nm}$ diameter range discrete catalytic nanoparticles synthesized in apoferritin cavity can be used for the growth of SWNTs on substrate by chemical vapor deposition (CVD) and diameter of nanotubes was controlled by getting hold on the structure of catalytic NPs in core. ${ }^{127}$ Moreover, apoferritin encapsulated Au NPs exhibited catalytic synthesis of single-walled carbon nanotubes (SWCNTs) on various substrates by chemical vapor deposition. ${ }^{146}$ In another similar attempt, ferritin cage loaded with catalytic Au NPs were immobilized to a silicon substrate for the growth of silicon nanowire (SiNW) by CVD. ${ }^{147}$

The apoferritin encapsulated homogeneous gold-silver alloy NPs aid in the catalytic reduction of 4-nitrophenol into 4-aminophenol in the presence of $\mathrm{NaBH}_{4}{ }^{152}$ A bimetallic nanoreactor is prepared by loading $\mathrm{Au}-\mathrm{Pd}$ NPs in apoferritin core that shows 2.5 -fold higher catalytic reactivity of olefin hydrogenation as compared to $\mathrm{Pd}^{0} \mathrm{NPs}$ in the cage. ${ }^{151}$

\section{Enzyme Immobilization}

Now a days, researchers are interested in stabilizing enzymes and retaining their activity as they are promising tools for wide range of applications including biocatalysis, bioassay, bioenergy conversion and environmental remediation. A large number of techniques are available for the enzyme immobilization but most of them have certain limitations, which include loss of enzymatic activity during immobilization, stability and low efficiency. Therefore, there is a need for development of new novel immobilization technique. A large number of inorganic materials are used for enzyme immobilization but they are not biocompatible.

Apoferritin provide a biocompatible nanosized container for the synthesis of biomaterials. It has been recently shown that the apoferritin can also be used in stabilizing enzymes and also to enhance their activity. Immobilization of glucose oxidase (GOx) has been reported on the surface of apoferritin by green synthetic approach. A glucose oxidase-biotin/streptavidin/biotinapoferritin conjugate (Apo-GOx) was formed by bridging with streptavidin. The Apo-GOx formed shows enhanced thermal and chemical stabilities. ${ }^{200}$

\section{Artificial Antioxidant}

A naturally occurring antioxidant enzyme includes the endogenous superoxide dismutase (SOD), but it is found to be incapable in protecting the cells from sudden oxidative damage. Therefore, current research is now focusing on the development of artificial antioxidant having a high ROS-scavenging capability and low cytotoxicity. Nanoceria (nano- $\mathrm{CeO}_{2}$ ) is now being studied because of their SOD mimetic activity and other properties, such as reversibility and auto regeneration. ${ }^{234,235}$

Recently, a nano- $\mathrm{CeO}_{2}$ has been constructed within the cavity of apoferritin protein cage, which improves biocompatibility and manipulate electron localization on the surface of nanoparticles thereby improving the ROSscavenging activity of this nanocomposite. It was suggested that the increase in redox activity of $\mathrm{CeO}_{2}$ is due to change in the surface morphology/surface defect or vacancies due to the charge transfer process that change the electron localization on the surface of nano- $\mathrm{CeO}_{2}$, which enhances its reducing activity. In vitro studies conducted on HepG2 cells confirmed the ROS scavenging activity of $\mathrm{CeO}_{2}$-apoferritin nanoparticles and internalization of $\mathrm{AFt}-\mathrm{CeO}_{2}$ by clathrin-mediated endocytosis, while the internalization of the nano- $\mathrm{CeO}_{2}$ by a macropinocytosis process. ${ }^{193}$ Moreover, a highly stable and catalytic Ptapoferritin nanoparticles were synthesized which enabled the cellular uptake of NPs via ferritin-receptor-mediated incorporation in human intestinal Caco-2 cells without any harmful interaction with the biological systems, such as lipid membranes or cell proteins as shown in Figure 7. It was able to quench superoxide anions and thereby reduced stress on cell ${ }^{191}$ and mimicked the activity of catalase and SOD.

Similarly, Pt nanoparticles loaded apoferritin cages possesses the activities of both catalase and peroxidase enzymes that play an important role in maintaining the redox balance of the body by scavenging the ROS. These Pt-apoferritin nanoparticles could decompose hydrogen peroxide to generate oxygen gas which confirmed the catalase activity of Pt-apoferritin. It produced distinctive colors with the organic dyes and hydrogen peroxide that indicated its peroxidase activity. The catalase activity increased with the increment in $\mathrm{pH}$ and temperature. ${ }^{190}$

\section{Magnetic Resonance Imaging (MRI) Contrasting Agents}

Much advancement has been made to understand the diseases at molecular level by utilizing molecular imaging techniques, which provide insight of the molecular 

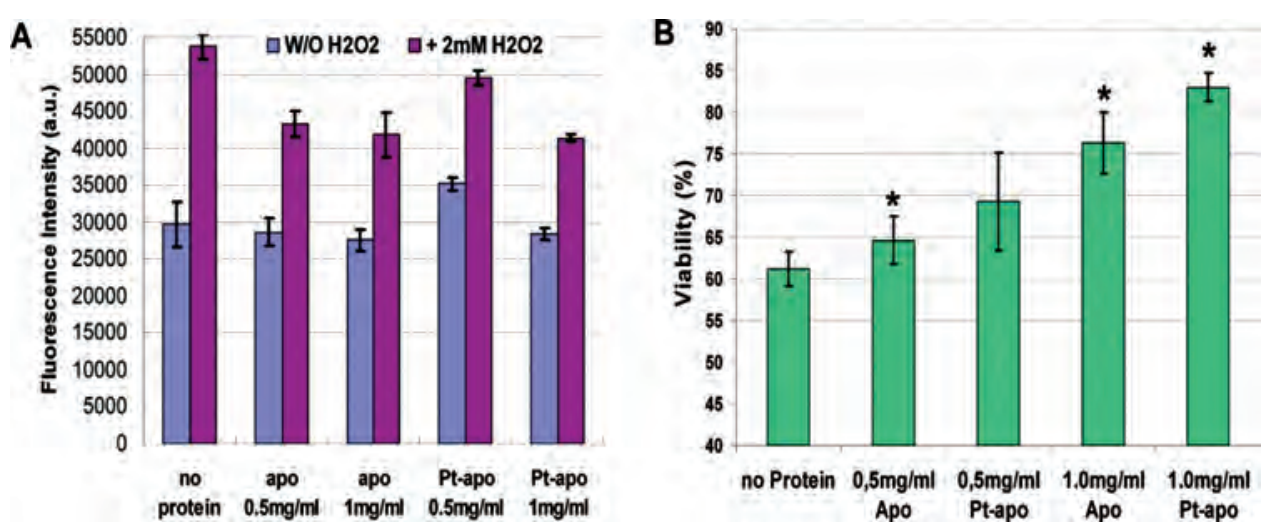

Figure 7. (A) Effect of apoferritin (apo) and Pt-apoferritin (Pt-apo) on $\mathrm{H}_{2} \mathrm{O}_{2}$-induced intracellular reactive oxygen species (ROS) generation in Caco-2 cells. After the $\mathrm{H}_{2} \mathrm{O}_{2}$-induction, the ROS levels of apo or Pt-apo treated cells are significantly lower than that of the control cells. (B) Effects of treatment with apo and Pt-apo on the viability of Caco-2 cells stressed with 5 mM $\mathrm{H}_{2} \mathrm{O}_{2}$. The viability was determined with the Cell Counting Kit-8. The viability of untreated (without both protein and $\mathrm{H}_{2} \mathrm{O}_{2}$ ) cells was set $100 \%$. Values marked with an asterisk are significantly different from each other. The results are represented by the mean \pm SD. Statistical analysis was done with the nonparametric two-tailed U-test, and a $p$-value of less than 0.05 was considered statistically significant. Reprinted with permission from [191], L. Zhang, et al., Reducing stress on cells with apoferritin-encapsulated platinum nanoparticles. Nano Lett. 10, 222 (2010). @ 2010, American Chemical Society.

events occurring inside the body. Amidst of these, MRI has emerged as a potential non-invasive tool in medical diagnosis of disease, that is capable of generating threedimensional images of human soft tissue by placing them in the long-wavelength radio waves and by acquiring relaxation times of excited nuclei mainly protons from water in the tissue. The contrast of MRI image depends upon many factors including the proton density of the tissues to be examined, the relative relaxation times $\mathrm{T} 1$ (spin lattice relaxation) and T2 (spin spin Relaxation), and instrumental parameters.

Now a days, mostly paramagnetic metal ions, such as high-spin $\mathrm{Mn}$ (II) and $\mathrm{Fe}$ (III) (five unpaired electrons) and Gd(III) (seven unpaired electrons) are used as MRI contrasting agent. Due to its unpaired electrons, it decreases the $\mathrm{T} 1$ and $\mathrm{T} 2$ relaxation times and enhances the signal observed. In order to nullify the toxic effect of some of these metal ions, their chelates such as gadolinium diethylenetriaminepentacetate (Gd-DTPA) have been used, which are stable and can be easily removed from the body through kidney. Moreover, ferritin level gets altered in many diseases, suggesting the use endogenous ferritin as a MRI reporter protein. It can assess the amount of iron in different tissues, such as liver, spleen, and brain. Thus it can be used to study lesions in the brains of Parkinson's patients ${ }^{236}$ and can also detect the atherosclerotic plaques of rabbits. ${ }^{237}$ Ferritins have also found to be used in monitoring transgene expression via MRI. ${ }^{238,239}$ The inherent property of ferritin comprising of a superparamagnetic ferrihydrite core makes it a suitable candidate as a MRI contrasting agent ${ }^{66}$ but due to the lower relaxivity of the endogenous ferritin, it has been restricted for clinical use. Therefore, enormous methods have been devised to enhance the relaxivity.
A ferritin iron oxide nanocomposite has been examined as an MRI contrasting agent for labeling macrophages involved in inflammatory diseases such as atherosclerosis, ${ }^{121}$ as these mineralized protein cages are easily taken up by the macrophages in vitro. Moreover, a T2 contrasting agent has been developed for MR imaging using an engineered ferritin from Archaeoglobus fulgidus, which showed higher relaxivity (R1 and R2 values) as compared to previously reported human ferritin iron oxide nanocomposites. ${ }^{129}$

A water-soluble gadolinium oxide nanoparticle has been synthesized inside the protein cage that showed potential as MRI contrasting agents. In general, apoferritin cage helps in storing Gd complexes and avoids their consequent toxicity. ${ }^{163,164}$ Similarly, a highly sensitive gadolinium loaded apoferritin probe has been used in MR visualization of human tumor-derived endothelial cells (TEC) transplanted into mice by targeting with a biotinylated peptide that binds to the selective surface molecule neural cell adhesion molecules (NCAM). Antiangiogenic therapy can utilize this approach. ${ }^{165}$ Recently, a new cationic gadolinium chelate (Gd-Me $\left.\mathrm{M}_{2} \mathrm{DO} 2 \mathrm{~A}\right)$ loaded apoferritin has been developed, which exhibited enhanced $\mathrm{T} 1$ proton relaxivity as much as 10-fold higher than gadoliniumtetraazacyclododecane tetraacetic acid (Gd-DOTA). The in vivo blood clearance time of apoferritin was enhanced by its surface modification with the help of dextran and has been utilized as contrasting agent in MR imaging of tumor in mice model. Single-dose toxicity test showed no side effects, indicating its biocompatibility. ${ }^{162}$

A highly ultrasensitive $\mathrm{T} 2$ contrasting agent has been developed from paramagnetic manganese ions synthesized inside the engineered apoferritin cages, these nanocomposites showed high $\mathrm{T} 2$ relaxivity and have the potential 
to be utilized in dual contrast MRI. ${ }^{189}$ The $\beta$-MnOOH loaded apoferritin have been found to be more effective than Gd-loaded apoferritin as it produces high relaxivity as compare to Gd-loaded apoferritin. ${ }^{188}$ Recently, it has been reported that Mn loaded apoferritin can be used as an in vivo MRI sensor for a massive oxidative process, such as melanin formation in melanoma cell. The Mn(III) gets reduced to $\mathrm{Mn}(\mathrm{II})$ inside the apoferritin cavity by the oxidation of L-3,4-dihydroxyphenylalanine (L-DOPA) to melanin, along with the cleared relaxation increment of water proton relaxation rate in both cultured melanoma cells and tumor animal models. This could be used for the early diagnosis of tumor. ${ }^{187}$

Recently, a tumor-environment-responsive nanocarrier has been formed by modifying the ferritin nanocage. This nanocarrier change its surface properties upon sensing a tumor-associated protease, matrix metalloproteinase-2 (MMP-2) and start agglomerating, which lead to enhancement of T2 relaxivity, suggesting its role to be used as contrast agent in magnetic resonance imaging (MRI). ${ }^{240}$

\section{Biocompatibility}

Apoferritin, self-assembled protein shell enhances the biocompatibility of nanoparticles present inside the apoferritin cage. In 1992, Hainfeld successfully encapsulated the radioactive uranium nuclei inside the ferritin cage. ${ }^{208}$ Later, the encapsulation of CdSe NPs inside the protein shell largely improved the water solubility and reduced the potential cytotoxicity of these NPs. ${ }^{177}$ Similarly, the presence of the apoferritin coat makes these NPs more water soluble and imparts stability. ${ }^{159}$ The water insoluble gold sulfide becomes soluble upon encapsulating in the protein cage. $^{149}$

A stable, water soluble and less toxic apoferritin- $\mathrm{PbS}$ nanocomposite has been developed and studied for its toxicity by conducting in vitro studies on MRC-5, MCF-7, MDA-468 cells. ${ }^{169}$ Moreover, the encapsulation of NPs in protein cage gives them a bio-recognizable identity and making them biocompatible. The encapsulation of $\mathrm{Pt}$ nanoparticles in apoferritin not only improves their biocompatibility but also change the internalization route along with an increase in their internalization in HepG2 cells by three times, via receptor-mediated endocytosis. ${ }^{192}$

\section{Other Applications}

Apart from biomedical and biological applications, apoferritin protein cages are also exploited for their use in various other applications. A drastic change has been observed in the property of particles after being encapsulated inside the apoferritin cage. Apoferritin encapsulated non magnetic Pd NPs shows permanent magnetism at room temperature. ${ }^{102}$ Moreover, the magnetic moment and exchange bias in all oxide materials encapsulated with ferritin cage can be tailored by adjusting their synthesis conditions. ${ }^{139}$ The CoPt encapsulated apoferritin could be used for data storage applications. ${ }^{117}$ Electrospraying and in-flight heating of ferritin produces controlled size, monodisperse aerosol particles that can be utilized as size standards for instrument calibration. ${ }^{186}$

Recently, a ferritin-based magnetic force microscopic probe has been developed that can be used for the magnetic force microscopy (MFM) imaging capable of (a)

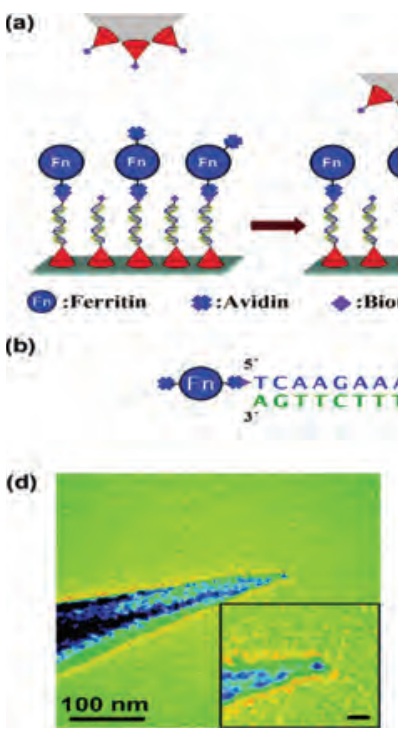

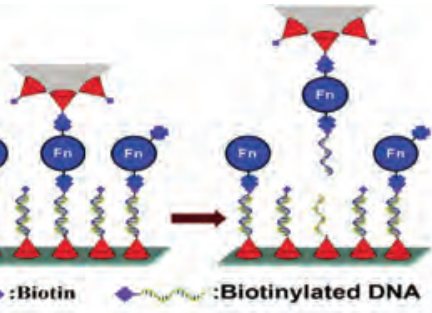

AATACCACATA
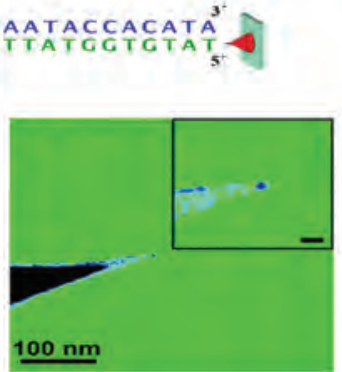

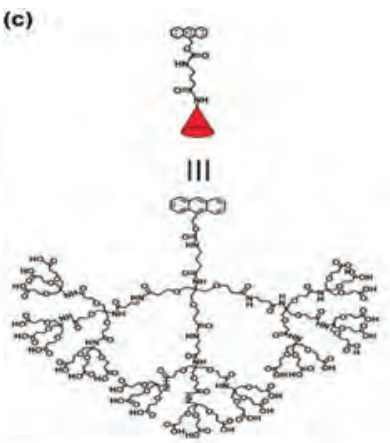

(e)

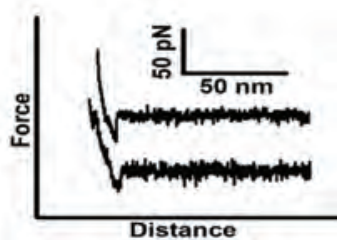

Figure 8. Picking up an avidin-ferritin conjugate. (a) Schematic diagram for the picking-up process. (b) DNA sequences used for the ferritin immobilization on a substrate. (c) Structure of the dendron molecule used for the tip and substrate modifications. (d) TEM images of AFM tips after ferritin attachment. A dark spot at the apex of a tip is evident (inset scale bar: $10 \mathrm{~nm}$ ). (e) Specific force curves, corresponding to the rupture of the hybridized DNA complex, were observed during the picking-up process. Reprinted with permissions from [241], D. Kim, et al., Ferritin-based new magnetic force microscopic probe detecting $10 \mathrm{~nm}$ sized magnetic nanoparticles. ACS Nano 6, 243 (2012). ( 2012, American Chemical Society. 
detecting magnetic nanoparticles of nearly $10 \mathrm{~nm}$ size and can sense the magnetic force coming from the magnetic materials and is also capable of detecting biomolecular interaction force with DNA on the surface as shown in Figure 8. In this process, a single ferritin molecule is placed at the end of the AFM tip through the use of the underlying dendron surface functionality. ${ }^{241}$

A flexible freestanding ultrathin protein films containing fluorescent $\mathrm{CdS}_{x} \mathrm{Se}_{1-x} / \mathrm{ZnS}$ nanocrystals has been prepared by filtration technique, which can find numerous suitable applications in the development of optoelectronic devices. ${ }^{242}$ A ferritin based bionanoparticle stabilized pickering emulsions have been used to prepare a bioinorganic composite capsules, such capsules would find their application in medical, cosmetic preparations and food technology. ${ }^{243}$ Apoferritin is also used as an ideal internal standard for the easy and automatic magnification determination of electron cryomicroscopy images which is typically used in biological cryomicroscopy. ${ }^{244}$ Moreover, a conjugate of packaging RNA (pRNA) with ferritin has been synthesized which could be used for the studies of programmed self-assembly in multi-component nanostructures. ${ }^{245}$

\section{CONCLUSION AND FUTURE PERSPECTIVES}

Protein based NPs have established nanosized delivery platforms for cancer treatment due to its inherent properties to accumulate at the tumor site through enhanced permeability and retention (EPR) effect and their versatile structure extends scope for multifunctionalization. Moreover, the extensive research in this field continuously encourages researchers to engineer these protein cages with diverse functionalities leading to the development of protein based theranostic nanocarriers. Meanwhile, the recent advances in this field have extended the use of these nanocarrier beyond therapeutic potentials into other fields, particularly biomedical applications such as MRI contrasting agent, nano based assays, biosensing devices etc. Still there is a long way ahead and numbers of challenges have to be overcome in this area to utilize the full potential of these protein-based architectures and implement their use in development of advanced biomaterials for various biomedical applications.

Acknowledgments: The authors acknowledge the financial support of the Department of Biotechnology (No. BT/PR6804/GBD/27/486/2012), and Science and Engineering Research Board (No. SR/FT/LS-57/2012), Government of India.

\section{REFERENCES}

1. H. S. Nalwa (ed.), Encyclopedia of Nanoscience and Nanotechnology, American Scientific Publishers, Los Angeles, CA (2004/2011), Vols. 1-25.

2. U. K. Sukumar, B. Bhushan, P. Dubey, I. Matai, A. Sachdev, and P. Gopinath, Emerging applications of nanoparticles for lung cancer diagnosis and therapy. Int. Nano Lett. 3, 45 (2013).

3. R. Misra, M. Upadhyay, and S. Mohanty, Nanoparticles as carriers for chemotherapeutic drugs: A review. J. Nanopharmaceutics Drug Delivery 1, 103 (2013).

4. B. K. Bindhani, U. K. Parida, S. K. Biswal, A. K. Panigrahi, and P. L. Nayak, Gold nanoparticles and their biomedical applications. Rev. Nanosci. Nanotechnol. 2, 247 (2013).

5. W. Lu and Y. Zu, Metal-based nanoparticles: Their potential clinical applications and limitations. Rev. Nanosci. Nanotechnol. 2, 208 (2013).

6. J. Cheng, Y. J. Gu, S. H. Cheng, and W. T. Wong, Surface functionalized gold nanoparticles for drug delivery. J. Biomed. Nanotechnol. 9, 1362 (2013).

7. P. Gopinath, S. K. Gogoi, P. Sanpui, A. Paul, A. Chattopadhyay, and S. S. Ghosh, Signaling gene cascade in silver nanoparticle induced apoptosis. Colloids Surf., B 77, 240 (2010).

8. A. S. Wadajkar, J. U. Menon, and K. T. Nguyen, Polymer-coated magnetic nanoparticles for cancer diagnosis and therapy. Rev. Nanosci. Nanotechnol. 1, 284 (2012).

9. G. Bhargavi, I. Matai. A. Sachdev, S. Uday Kumar, and P. Gopinath, Microwave assisted synthesis of chitosan nanorods and assessments of its antibacterial activity against GFP-expressing antibiotic resistant E.coli. J. Chitin Chitosan Sci. 1, 1 (2013).

10. N. Rozanova and J. Z. Zhang, Metal and magnetic nanostructures for cancer diagnosis and therapy. Rev. Nanosci. Nanotechnol. 2, 29 (2013).

11. A. Kleinauskas, J. K. Kim, G. H. Choi, H. T. Kim, K. Røe, and P. Juzenas, Superparamagnetic magnetite nanoparticles for cancer theranostics. Rev. Nanosci. Nanotechnol. 1, 271 (2012).

12. R. Singh and H. S. Nalwa, Medical applications of nanoparticles in biological imaging, cell labeling, antimicrobial agents, and anticancer nanodrugs. J. Biomed. Nanotechnol. 7, 489 (2011).

13. R. Tivony, L. Larush, O. Sela-Tavor, and S. Magdassi, Biomedical imaging of colorectal cancer by near infrared fluorescent nanoparticles. J. Biomed. Nanotechnol. 10, 1041 (2014).

14. A. Sachdev, I. Matai, S. Uday Kumar, B. Bhushan, P. Dubey, and P. Gopinath, A novel one-step synthesis of PEG passivated multicolour fluorescent carbon dots for potential biolabeling application. RSC Adv. 3, 16958 (2013).

15. I. Matai, A. Sachdev, P. Dubey, S. Uday Kumar, B. Bhushan, and P. Gopinath, Antibacterial activity and mechanism of $\mathrm{Ag}-\mathrm{ZnO}$ nanocomposite on S. aureus and GFP-expressing antibiotic resistant E. coli. Colloids Surf. B 115, 359 (2014).

16. G. Sahni, P. Gopinath, and P. Jeevanandam, A novel thermal decomposition approach to synthesize hydroxypatite-silver nanocomposite and their antibacterial action against GFPexpressing antibiotic resistant E.coli. Colloids Surf. B 103, 441 (2013).

17. H. S. Nalwa and T. Webster (eds.), Cancer Nanotechnology: Nanomaterials for Cancer Diagnosis and Therapy, American Scientific Publishers, Los Angeles, CA (2007).

18. G. Zhang, $X$. Zeng, and $P$. Li, Nanomaterials in cancer-therapy drug delivery system. J. Biomed. Nanotechnol. 9, 741 (2013).

19. S. Singh and H. S. Nalwa, Nanotechnology and health safetytoxicity and risk assessments of nanostructured materials on human health. J. Nanosci. Nanotechnol. 7, 3048 (2007).

20. H. S. Nalwa (ed.), Handbook of Nanostructured Biomaterials and Their Applications in Nanobiotechnology, American Scientific Publishers, Los Angeles (2005), Vols. 1-2.

21. H. S. Nalwa (ed.), Handbook of Nanostructured Materials and Nanotechnology, Academic Press, San Diego, CA (2000), Vols. 1-5.

22. P. Arosio and S. Levi, Ferritin, iron homeostasis, and oxidative damage. Free Radic. Biol. Med. 33, 457 (2002).

23. T. Haikarainen and A. C. Papageorgiou, Dps-like proteins: Structural and functional insights into a versatile protein family. Cell Mol. Life Sci. 67, 341 (2010). 
24. M. Okuda, Y. Suzumoto, K. Iwahori, S. Kang, M. Uchida, T. Douglas, and I. Yamashita, Bio-templated CdSe nanoparticle synthesis in a cage shaped protein, Listeria-Dps, and their two dimensional ordered array self-assembly. Chem. Coтmun. 46, 8797 (2010).

25. L. Liepold, S. Anderson, D. Willits, L. Oltrogge, J. A. Frank, T. Douglas, and M. Young, Viral capsids as MRI contrast agents. Magn. Reson. Med. 58, 871 (2007).

26. E. Gillitzer, D. Willits, M. Young, and T. Douglas, Chemical modification of a viral cage for multivalent presentation. Chem. Commun. (Camb) 20, 2390 (2002).

27. S. Brumfield, D. Willits, L. Tang, J. E. Johnson, T. Douglas, and M. Young, Heterologous expression of the modified coat protein of Cowpea chlorotic mottle bromovirus results in the assembly of protein cages with altered architectures and function. J. Gen. Virol. 85, 1049 (2004).

28. K. K. Kim, R. Kim, and S. H. Kim, Crystal structure of a small heat-shock protein. Nature 394, 595 (1998).

29. L. O. Liepold, M. J. Abedin, E. D. Buckhouse, J. A. Frank, M. J. Young, and T. Douglas, Supramolecular protein cage composite MR contrast agents with extremely efficient relaxivity properties. Nano Lett. 9, 4520 (2009).

30. M. L. Flenniken, D. A. Willits, A. L. Harmsen, L. O. Liepold, A. G. Harmsen, M. J. Young, and T. Douglas, Melanoma and lymphocyte cell-specific targeting incorporated into a heat shock protein cage architecture. Chem Biol. 13, 161 (2006).

31. B. Worsdorfer, K. J. Woycechowsky, and D. Hilvert, Directed evolution of a protein container. Science 331, 589 (2011).

32. B. Worsdorfer, Z. Pianowski, and D. Hilvert, Efficient in vitro encapsulation of protein cargo by an engineered protein container. J. Am. Chem. Soc. 134, 909 (2012).

33. K. Schott, R. Ladenstein, A. König, and A. Bacher, The lumazine synthase-riboflavin synthase complex of Bacillus subtilis. Crystallization of reconstituted icosahedral beta-subunit capsids. J. Biol. Chem. 265, 12686 (1990).

34. K. M. Bromley, A. J. Patil, A. W. Perriman, G. Stubbs, and S. Mann, Preparation of high quality nanowires by tobacco mosaic virus templating of gold nanoparticles. J. Mater. Chem. 18, 4796 (2008).

35. W. Shenton, T. Douglas, M. Young, G. Stubbs, and S. Mann, Inorganic-organic nanotubes composites from template mineralization of tobacco mosaic virus. Adv. Mater. 11, 253 (1999).

36. S. Kang, M. Uchida, A. O'Neil, R. Li, P. E. Prevelige, and T. Douglas, Implementation of P22 Viral Capsids as Nanoplatforms. Biomacromolecules 11, 2804 (2010).

37. J. E. Johnson and W. Chiu, DNA packaging and delivery machines in tailed bacteriophages. Cur. Opin. Struct. Biol. 17, 237 (2007).

38. E. A. Anderson, S. Isaacman, D. S. Peadbody, E. Y. Wang, J. W. Canary, and K. Kirshenbaum, K. Viral nanoparticles donning a paramagnetic coat: Conjugation of MRI contrast agents to the MS2 capsid. Nano Lett. 6, 1160 (2006).

39. J. M. Hooker, J. P. O'Neil, D. W. Romanini, S. E. Taylor, and M. B. Francis, Genome-free viral capsids as carriers for positron emission tomography radiolabels. Mol. Imaging Biol. 10, 182 (2008).

40. E. W. Kovacs, J, M. Hooker, D. W. Romanini, P. G. Holder, K. E. Berry, and M. B. Francis, Dual-surface-modified bacteriophage MS2 as an ideal scaffold for a viral capsid-based drug delivery system. Bioconjug. Chem. 18, 1140 (2007)

41. M. R. Mozafari, Nanocarrier Technologies: Frontiers of Nanotherapy, edited by M. R. Mozafari, Springer, Netherlands (2006), pp. $1-16$.

42. N. S. Templeton, Cationic liposome-mediated gene delivery in vivo. Biosci. Rep. 22, 283 (2002).

43. M. V. Laufberger, Sur la cristallisation de la ferritine. Bull. Soc. Chim. Biol. 19, 1575 (1937).

44. D. M. Lawson, P. J. Artymiuk, S. J. Yewdall, J. M. Smith, J. C. Livingstone, A. Treffry, A. Luzzago, S. Levi, P. Arosio,
G. Cesareni, C. D. Thomas, W. V. Shaw, and P. M. Harrison, Solving the structure of human $\mathrm{H}$ ferritin by genetically engineering intermolecular crystal contacts. Nature 349, 541 (1991).

45. S. C. Andrews, A. K. Robinson, and F. Rodriguez-Quinones, Bacterial iron homeostasis. FEMS Microbiol. Rev. 27, 215 (2003).

46. E. C. Theil, Ferritin: Structure, gene regulation, and cellular function in animals, plants, and microorganisms. Аnnu. Rev. Biochem. 56, 289 (1987).

47. E. Chiancone and P. Ceci, The multifaceted capacity of Dps proteins to combat bacterial stress conditions: Detoxification of iron and hydrogen peroxide and DNA binding. Biochim. Biophys. Acta 1800, 798 (2010).

48. X. Liu and E. C. Theil, Ferritins: Dynamic management of biological iron and oxygen chemistry. Acc Chem. Res. 38, 167 (2005).

49. A. Ilari, S. Stefanini, E. Chiancone, and D. Tsernoglou, The dodecameric ferritin from Listeria innocua contains a novel intersubunit iron-binding site. Nat. Struct. Biol. 7, 38 (2000).

50. R. R. Crichton and C. F. A. Bryce, Subunit interactions in horse spleen apoferritin. Dissociation by extremes of $\mathrm{pH}$. Biochem. J. 133, 289 (1973).

51. S. Stefanini, S. Cavallo, C. Q. Wang, P. Tataseo, P. Vecchini, A. Giartosio, and E. Chiancone, Thermal stability of horse spleen apoferritin and human recombinant $\mathrm{H}$ apoferritin. Arch. Biochem. Biophys. 325, 58 (1996).

52. P. Ceci, A. Ilari, E. Falvo, L. Giangiacomo, and E. Chiancone, Reassessment of protein stability, DNA binding, and protection of mycobacterium smegmatis Dps. J. Biol. Chem. 280, 34776 (2005).

53. R. Chiaraluce, V. Consalvi, S. Cavallo, A. Ilari, S. Stefanini, and E. Chiancone, The unusual dodecameric ferritin from listeria innocua dissociates below $\mathrm{pH}$ 2.0. Eur. J. Biochem. 267, 5733 (2000).

54. S. Roy, R. Saraswathi, S. Gupta, K. Sekar, D. Chatterji, and M. Vijayan, Role of $\mathrm{N}$ and C-terminal tails in DNA binding and assembly in Dps: Structural studies of mycobacterium smegmatis Dps deletion mutants. J. Mol. Biol. 370, 752 (2007).

55. G. Bellapadrona, S. Stefanini, C. Zamparelli, E. C. Theil, and E. Chiancone, Iron translocation into and out of Listeria innocua Dps and size distribution of the protein-enclosed nanomineral are modulated by the electrostatic gradient at the 3-fold "ferritin like" pores. J. Biol. Chem. 284, 19101 (2009).

56. S. Haldar, L. E. Bevers, T. Tosha, and E. C. Theil, Moving iron through ferritin protein nanocages depends on residues throughout each four $\alpha$-helix bundle subunit. J. Biol. Chem. 286, 25620 (2011).

57. A. R. Stiles, J. G. McDonald, D. R. Bauman, and D. W. Russell, CYP7B1: One cytochrome P450, two human genetic diseases, and multiple physiological functions. J. Biol. Chem. 284, 28485 (2009).

58. G. L. Semenza, Involvement of oxygen-sensing pathways in physiologic and pathologic erythropoiesis. Blood 114, 2015 (2009).

59. P. Arosio, R. Ingrassia, and P. Cavadini, Ferritins: A family of molecules for iron storage, antioxidation and more. Biochim. Biophys. Acta 1790, 589 (2009).

60. S. Abe, K. Hirata, T. Ueno, K. Morino, N. Shimizu, M. Yamamoto, M. Takata, E. Yashima, and Y. Watanabe, Polymerization of phenylacetylene by rhodium complexes within a discrete space of apoferritin. J. Am. Chem. Soc. 131, 6958 (2009).

61. P. D. Hempstead, S. J. Yewdall, A. R. Fernie, D. M. Lawson, P. J. Artymiuk, D. W. Rice, G. C. Ford, and P. M. Harrison, Comparison of the three-dimensional structures of recombinant human $\mathrm{H}$ and horse L ferritins at high resolution. J. Mol. Biol. 268, 424 (1997).

62. D. M. Jr. Kurtz, Structural similarity and functional diversity in diiron-oxo proteins. J. Biol. Inorg. Chem. 2, 159 (1997).

63. A. I. Kuklin, T. N. Murugova, O. I. Ivankov, A. V. Rogachev, D. V. Soloviov, Y. S. Kovalev, A. V. Ishchenko, A. Zhigunov, T. S. Kurkin, and V. I. Gordeliy, Comparative study on low resolution structures of apoferritin via SANS and SAXS. J. Phys.: Conf. Ser. 351, 012009 (2012). 
64. V. J. Wade, S. Levi, P. Arosio, A. Treffry, P. M. Harrison, and S. Mann, Influence of site-directed modifications on the formation of iron cores in ferritin. J. Mol. Biol. 221, 1443 (1991).

65. S. Levi, A. Luzzago, G. Cesareni, A. Cozzi, F. Franceschinelli, A. Albertini, and P. Arosio, Mechanism of ferritin iron uptake: Activity of the $\mathrm{H}$-chain and deletion mapping of the ferro-oxidase site. A study of iron uptake and ferro-oxidase activity of human liver, recombinant $\mathrm{H}$-chain ferritins, and of two H-chain deletion mutants. J. Biol. Chem. 263, 18086 (1988).

66. P. M. Harrison and P. Arosio, The ferritins: Molecular properties, iron storage function and cellular regulation. Biochim. Biophys. Acta 1275, 161 (1996).

67. S. Ghosh, S. Hevi, and S. L. Chuck, Regulated secretion of glycosylated human ferritin from hepatocytes. Blood 103, 2369 (2004).

68. J. D. Lopez-Castro, J. J. Delgado, J. A. Perez-Omil, N. Gálvez, R. Cuesta, R. K. Watt, and J. M. Domínguez-Vera, A new approach to the ferritin iron core growth: Influence of the $\mathrm{H} / \mathrm{L}$ ratio on the core shape. Dalton Trans. 41, 1320 (2012).

69. A. Sennuga, J. van Marwijk, and C. G. Whiteley, Multiple fold increase in activity of ferroxidase-apoferritin complex by silver and gold nanoparticles. Nanomed. Nanotechnol. Biol. Med. 9, 185 (2013).

70. A. Sennuga, J. van Marwijk, and C. G. Whiteley, Ferroxidase activity of apoferritin is increased in the presence of platinum nanoparticles. Nanotechnology 23, 035102 (2012).

71. A. Sigel and H. Sigel, (eds.), Iron Transport and Storage Microorganisms, Plants, and Animals. Metal Ions in Biological Systems, Marcel Dekker, New York (1988), Vol. 35.

72. N. Galvez, B. Ruiz, R. Cuesta, E. Colacio, and J. M. DominguezVera, Release of iron from ferritin by aceto- and benzohydroxamic acids. Inorg. Chem. 44, 2706 (2005).

73. E. C. Theil, X. S. Liu, and T. Tosha, Gated pores in the ferritin protein nanocage. Inorg. Chim. Acta 361, 868 (2008).

74. T. Douglas and D. R. Ripoll, Calculated electrostatic gradients in recombinant human H-chain ferritin. Protein Sci. 7, 1083 (1998).

75. Y. G. Cheng and N. D. Chasteen, Role of phosphate in initial iron deposition in apoferritin. Biochemistry 30, 2947 (1991).

76. S. H. Juan and S. D. Aust, The effect of putative nucleation sites on the loading and stability of iron in ferritin. Arch. Biochem. Biophys. 350, 259 (1998).

77. P. Santambrogio, S. Levi, A. Cozzi, B. Corsi, and P. Arosio, Evidence that the specificity of iron incorporation into homopolymers of human ferritin L- and H-chains is conferred by the nucleation and ferroxidase centres. Biochem. J. 314, 139 (1996).

78. R. K. Watt, R. J. Hilton, and D. M. Graff, Oxido-reduction is not the only mechanism allowing ions to traverse the ferritin protein shell. Biochim. Biophys. Acta 1800, 745 (2010).

79. M. Wolszczak and J. Gajda, Iron release from ferritin induced by light and ionizing Radiation. Res. Chem. Intermed. 36, 549 (2010).

80. R. R. Crichton, F. Roman, F. Roland, E. Pagues, A. Paques, and E. Vandamme, Ferritin iron deposition and mobilization. J. Mol. Catal. 7, 267 (1980).

81. E. Vichinsky, Consensus document for transfusion-related iron overload. Semin. Hematol. 38, 2 (2001).

82. F. C. Meldrum, B. R. Heywood, and S. Mann, Magnetoferritin: In vitro synthesis of a novel magnetic protein. Science 257, 522 (1992).

83. J. W. Bulte, T. Douglas, S. Mann, R. B. Frankel, B. M. Moskowitz, R. A. Brooks, C. D. Baumgarner, J. Vymazal, M. P. Strub, and J. A. Frank, Magnetoferritin: Characterization of a novel superparamagnetic MR contrast agent. J. Magn. Reson. Imaging 4, 497 (1994).

84. M. Allen, D. Willits, M. Young, and T. Douglas, Constrained synthesis of cobalt oxide nanomaterials in the 12 -subunit protein cage from Listeria innocua. Inorg. Chem. 42, 6300 (2003).

85. M. Allen, D. Willits, J. Mosolf, M. Young, and T. Douglas, Protein cage constrained synthesis of ferrimagnetic iron oxide nanoparticles. Adv. Mater. 14, 1562 (2002).
86. S. Kang, C. C. Jolley, L. O. Liepold, M. Young, and T. Douglas, From metal binding to nanoparticle formation: Monitoring biomimetic iron oxide synthesis within protein cages using mass spectrometry. Angew. Chem. Int. Ed. Engl. 48, 4772 (2009).

87. K. Iwahori and I. Yamashita, Size-controlled one-pot synthesis of fluorescent cadmium sulfide semiconductor nanoparticles in an apoferritin cavity. Nanotechnology 19, 495601 (2008).

88. S. Kang, J. Lucon, Z. B. Varpness, L. Liepold, M. Uchida, D. Willits, M. Young, and T. Douglas, Monitoring biomimetic platinum nanocluster formation using mass spectrometry and clusterdependent $\mathrm{H} 2$ production. Angew. Chem. Int. Ed. Engl. 47, 7845 (2008).

89. T. Ueno, M. Suzuki, T. Goto, T. Matsumoto, K. Nagayama, and Y. Watanabe, Size-selective olefin hydrogenation by a Pd nanocluster provided in an apoferritin cage. Angew. Chem. Int. Ed. 43, 2527 (2004).

90. I. Yamashita, Fabrication of a two-dimensional array of nanoparticles using ferritin molecule. Thin Solid Films 393, 12 (2001).

91. T. Douglas, D. P. Dickson, S. Betteridge, J. Charnock, C. D. Garner, and S. Mann, Synthesis and structure of an iron(III) sulfide-ferritin bioinorganic nanocomposite. Science 269, 54 (1995).

92. M. T. Klem, M. Young, and T. Douglas, Biomimetic synthesis of photoactive $\alpha-\mathrm{Fe}_{2} \mathrm{O}_{3}$ templated by the hyperthermophilic ferritin from Pyrococus furiosus. J. Mater. Chem. 20, 65 (2010).

93. J. Tatur, P. L. Hagedoorn, M. L. Overeijnder, and W. R. Hagen, A highly thermostable ferritin from the hyperthermophilic archaeal anaerobe pyrococcus furiosus. Extremophiles 10, 139 (2006).

94. M. J. Parker, M. A. Allen, B. Ramsay, M. T. Klem, M. Young, and T. Douglas, Expanding the temperature range of biomimetic synthesis using a ferritin from the hyperthermophile pyrococcus furiosus. Chem. Mater. 20, 1541 (2008).

95. R. Tsukamoto, M. Muraoka, Y. Fukushige, T. Kawaguchi, Y. Nakatsuji, and I. Yamashita, (eds.), The effect of PEGylation of ferritin on the biomineralization of $\mathrm{Co}_{3} \mathrm{O}_{4}$ core, Proceedings of the 2006 WSEAS Int. Conf. on Cellular and Molecular Biology, Biophysics and Bioengineering, Athens, Athens, Greece, July (2006).

96. C. A. Butts, J. Swift, S. G. Kang, L. Di Costanzo, D. W. Christianson, J. G. Saven, and I. J. Dmochowski, Directing noble metal ion chemistry within a designed ferritin protein. Biochemistry 47, 12729 (2008).

97. M. Sengonul, A. Sousa, and M. Libera, Selective adsorption of surface-modified ferritin on a phase-separated polymer blend. Colloids. Surf. B. Biointerfaces 73, 152 (2009).

98. B. Zheng, I. Yamashita, M. Uenuma, K. Iwahori, M. Kobayashi, and Y. Uraoka, Site-directed delivery of ferritin-encapsulated gold nanoparticles. Nanotechnology 2, 045305 (2010).

99. S. Kanbak-Aksu, M. Nahid Hasan, W. R. Hagen, F. Hollmann, D. Sordi, R. A. Sheldon, and I. W. Arends, Ferritin-supported palladium nanoclusters: Selective catalysts for aerobic oxidations in water. Chem. Commun. (Camb) 48, 5745 (2012).

100. T. Ueno, M. Suzuki, T. Goto, T. Matsumoto, K. Nagayama, and Y. Watanabe, Size-selective olefin hydrogenation by a Pd nanocluster provided in an apo-ferritin cage. Angew. Chem. Int. Ed. Engl. 43, 2527 (2004).

101. S. Abe, J. Niemeyer, M. Abe, Y. Takezawa, T. Ueno, T. Hikage, G. Erker, Y. Watanabe, Control of coordination structure of organometallic palladium complexes in an apo-ferritin cage. J. Am. Chem. Soc. 130, 10512 (2008).

102. M. Clemente-Leon, E. Coronado, A. Soriano-Portillo, N. Galvez, and J. M. Dominguez-Vera, Permanent magnetism in apoferritinencapsulated Pd nanoparticles. J. Mater. Chem. 17, 49 (2007).

103. X. Lin, J. Xie, G. Niu, F. Zhang, H. Gao, M. Yang, Q. Quan, M. A. Aronova, G. Zhang, S. Lee, R. Leapman, and X. Chen, Chimeric ferritin nanocages for multiple function loading and multimodal imaging. Nano Lett. 11, 814 (2011). 
104. D. Ensign, M. Young, and T. Douglas, Photocatalytic synthesis of copper colloids from CuII by the ferrihydrite core of ferritin. Inorg. Chem. 43, 3441 (2004).

105. N. Galvez, B. Fernandez, E. Valero, P. Sanchez, R. Cuesta, and J. M. Dominguez-Vera, Apoferritin as a nanoreactor for preparing metallic nanoparticles. C. R. Chimi 11, 1207 (2008).

106. T. Rakshit and R. Mukhopadhyay, Solid-state electron transport in $\mathrm{Mn}-$, Co-, holo-, and Cu-ferritins: Force-induced modulation is inversely linked to the protein conductivity. J. Colloid Interf. Sci. 388, 282 (2012).

107. K. Iwahori, R. Takagi, N. Kishimoto, and I. Yamashita, A size controlled synthesis of $\mathrm{CuS}$ nano-particles in the protein cage, apoferritin. Mater. Lett. 65, 3245 (2011).

108. N. Galvez, P. Sanchez, and J. M. Dominguez-Vera, Preparation of $\mathrm{Cu}$ and $\mathrm{CuFe}$ prussian blue derivative nanoparticles using the apoferritin cavity as nanoreactor. Dalton Trans. 15, 2492 (2005).

109. N. Galvez, P. Sanchez, J. M. Dominguez-Vera, A. Soriano-Portillo, M. Clemente-Leon, and E. Coronado, Apoferritin-encapsulated Ni and Co superparamagnetic nanoparticles. J. Mater. Chem. 16, 2757 (2006).

110. J. W. Kim, S. H. Choi, P. T. Lillehei, S. H. Chu, G. C. King, and G. D. Watt, Cobalt oxide hollow nanoparticles derived by biotemplating. Chem. Commun. (Camb) 32, 4101 (2005).

111. S. Kashanian, F. A. Tarighat, and R. Rafipour, Biomimetic synthesis of cobalt nanoparticle using apoferritin and its application in electrochemical reaction to detect glucose. New Biotechnol. 25S, S376 (2009).

112. S. Kashanian, F. A. Tarighat, R. Rafipour, and M. A. Tarighat, Biomimetic synthesis and characterization of cobalt nanoparticles using apoferritin, and investigation of direct electron transfer of $\mathrm{Co}(\mathrm{NPs})$-ferritin at modified glassy carbon electrode to design a novel nanobiosensor. Mol. Biol. Rep. 39, 8793 (2012).

113. B. Zhang, J. N. Harb, R. C. Davis, J. W. Kim, S. H. Chu, S. Choi, T. Miller, and G. D. Watt, Kinetic and thermodynamic characterization of the cobalt and manganese oxyhydroxide cores formed in horse spleen ferritin. Inorg. Chem. 44, 3738 (2005).

114. H. A. Hosein, D. R. Strongin, M. Allen, and T. Douglas, Iron and cobalt oxide and metallic nanoparticles prepared from ferritin. Langmuir 20, 10283 (2004).

115. B. Zhang, J. N. Harb, R. C. Davis, S. Choi, J. W. Kim, T. Miller, S. H. Chu, and G. D. Watt, Electron exchange between Fe(II)-horse spleen ferritin and $\mathrm{Co}(\mathrm{III}) / \mathrm{Mn}(\mathrm{III})$ reconstituted horse spleen and azotobacter vinelandii ferritins. Biochemistry 45, 5766 (2006).

116. R. M. Kramer, C. Li, D. C. Carter, M. O. Stone, and R. R. Naik, Engineered protein cages for nanomaterial synthesis. J. Am. Chem. Soc. 126, 13282 (2004).

117. B. Warne, O. I. Kasyutich, E. L. Mayes, J. A. L. Wiggins, and K. K. M. Wong, Self assembled nanoparticulate Co:Pt for data storage applications. IEEE Trans. Magn. 36, 3009 (2000).

118. N. Galvez, E. Valero, M. Ceolin, S. Trasobares, M. Lopez-Haro, J. Calvino, and J. M. Domínguez-Vera, A bioinspired approach to the synthesis of bimetallic $\mathrm{CoNi}$ nanoparticles. Inorg. Chem. 49, 1705 (2010).

119. M. Okuda, K. Iwahori, I. Yamashita, and H. Yoshimura, Fabrication of nickel and chromium nanoparticles using the protein cage of apoferritin. Biotechnol. Bioeng. 84, 187 (2003).

120. M. J. Parker, M. A. Allen, B. Ramsay, M. T. Klem, and M. Young, Expanding the temperature range of biomimetic synthesis using a ferritin from the hyperthermophile pyrococcus furiosus. Chem. Mater. 20, 1541 (2008).

121. M. Uchida, M. Terashima, C. H. Cunningham, Y. Suzuki, D. A. Willits, A. F. Willis, P. C. Yang, P. S. Tsao, M. V. McConnell, M. J. Young, and T. Douglas, A human ferritin iron oxide nanocomposite magnetic resonance contrast agent. Magn. Reson. Med. 60, 1073 (2008).

122. M. Uchida, M. L. Flenniken, M. Allen, D. A. Willits, B. E. Crowley, S. Brumfield, A. F. Willis, L. Jackiw, M. Jutila, and M. J.
Young, Targeting of cancer cells with ferrimagnetic ferritin cage nanoparticles. J. Am. Chem. Soc. 128, 16626 (2006).

123. M. Zborowski, C. B. Fuh, R. Green, N. J. Baldwin, S. Reddy, T. Douglas, S. Mann, and J. J. Chalmers, Immunomagnetic isolation of magnetoferritin-labeled cells in a modified ferrograph. Cytometry 24, 251 (1996).

124. R. M. Kramer, L. A. Sowards, M. J. Pender, M. J. Stone, and R. R. Naik, Constrained iron catalysts for single walled carbon nanotube growth. Langmuir 21, 8466 (2005).

125. V. V. Nikandrov, C. K. Gratzel, J. E. Moser, and M. Gratzel, Light induced redox reactions involving mammalian ferritin as photocatalyst. J. Photochem. Photobiol. B 41, 83 (1997).

126. I. Kim, H. A. Hosein, D. R. Strongin, and T. Douglas, Photochemical reactivity of ferritin for $\mathrm{CR}(\mathrm{VI})$ reduction. Chem. Mater. 14, 4874 (2002).

127. Y. Li, W. Kim, Y. Zhang, M. Rolandi, D. Wang, and H. Dai, Growth of single-walled carbon nanotubes from discrete catalytic nanoparticles of various sizes. J. Phys. Chem. B 105, 11424 (2001).

128. L. Vannucci, E. Falvo, M. Fornara, P. Di Micco, O. Benada, J. Krizan, J. Svoboda, K. Hulikova-Capkova, V. Morea, A. Boffi, and P. Ceci, Selective targeting of melanoma by PEG-masked protein-based multifunctional nanoparticles. Int. J. Nanomedicine 7, 1489 (2012).

129. B. Sana, E. Johnson, K. Sheah, C. L. Poh, and S. Lim, Iron-based ferritin nanocore as a contrast agent. Biointerphases 5, 48 (2010).

130. M. Terashima, M. Uchida, H. Kosuge, P. S. Tsao, M. J. Young, S. M. Conolly, T. Douglas, and M. V. McConnell, Human ferritin cages for imaging vascular macrophages. Biomaterials 32, 1430 (2011).

131. M. Okuda, J. C. Eloi, S. E. W. Jones, A. Sarua, R. M. Richardson, and W. Schwarzacher, Fe3O4 nanoparticles: Protein-mediated crystalline magnetic superstructures. Nanotechnology 23, 415601 (2012).

132. K. Li, Z. P. Zhang, M. Luo, X. Yu, Y. Han, H. P. Wei, Z. Q. Cui, and X. E. Zhang, Multifunctional ferritin cage nanostructures for fluorescence and MR imaging of tumor cells. Nanoscale 4, 188 (2012).

133. F. C. Meldrum, V. J. Wade, D. L. Nimmo, B. R. Heywood, and S. Mann, Synthesis of inorganic nanophase materials in supramolecular protein cages. Nature 349, 684 (1991).

134. M. T. Klem, J. Mosolf, M. Young, and T. Douglas, Photochemical mineralization of europium, titanium, and iron oxyhydroxide nanoparticles in the ferritin protein cage. Inorg. Chem. 47, 2237 (2008).

135. E. C. Theil, H. Chen, C. Miranda, H. Janser, B. Elsenhans, M. T. Nunez, F. Pizarro, K. Schumann, Absorption of iron from ferritin is independent of heme iron and ferrous salts in women and rat intestinal segments. J. Nutr. 142, 478 (2012).

136. M. Okuda, Y. Kobayashi, K. Suzuki, K. Sonoda, T. Kondoh, A. Wagawa, A. Kondo, and H. Yoshimura, Self-organized inorganic nanoparticle arrays on protein lattices. Nano Lett. 5, 991 (2005).

137. B. Zheng, M. Uenuma, K. Iwahori, N. Okamoto, M. Naito, Y. Ishikawa, Y. Uraoka, and I. Yamashita, Sterically controlled docking of gold nanoparticles on ferritin surface by DNA hybridization. Nanotechnology 22, 275312 (2011).

138. M. Tominaga, L. Han, L. Wang, M. M. Maye, J. Luo, N. Kariuki, and C. J. Zhong, Formation of water-soluble iron oxide nanoparticles derived from iron storage protein. J. Nanosci. Nanotechnol. 4, 708 (2004)

139. M. T. Klem, D. A. Resnick, K. Gilmore, M. Young, Y. U. Idzerda, and T. Douglas, Synthetic control over magnetic moment and exchange bias in all-oxide materials encapsulated within a spherical protein cage. J. Am. Chem. Soc. 129, 197 (2007).

140. J. Polanams, A. D. Ray, and R. K. Watt, Nanophase iron phosphate, iron arsenate, iron vanadate, and iron molybdate minerals synthesized within the protein cage of ferritin. Inorg. Chem. 44, 3203 (2005). 
141. Y. J. Kang, M. Uchida, H. Shin, T. Douglas, and S. Kang, Biomimetic FePt nanoparticles synthesis within Pyrococcus furiosus ferritins and their layer-by-layer formation. Soft Matter 7, 11708 (2011).

142. J. M. Dominguez-Vera, Iron(III) complexation of Desferrioxamine B encapsulated in apoferritin. J. Inorg. Biochem. 98, 469 (2004).

143. L. Zhang, W. Fischer, E. Pippel, G. Hause, M. Brandsch, and M. Knez, Receptor-mediated cellular uptake of nanoparticles: A switchable delivery system. Small 7, 1538 (2011).

144. J. D. Keyes, R. J. Hilton, J. Farrer, and R. K. Watt, Ferritin as a photocatalyst and scaffold for gold nanoparticle synthesis. J. Nanopart. Res. 13, 2563 (2011).

145. C. Sun, H. Yang, Y. Yuan, X. Tian, L. Wang, Y. Guo, L. Xu, J. Lei, N. Gao, G. J. Anderson, X. J. Liang, C. Chen, Y. Zhao, and G. Nie, Controlling assembly of paired gold clusters within apoferritin nanoreactor for invivo kidney targeting and biomedical imaging. J. Am. Chem. Soc. 133, 8617 (2011).

146. D. Takagi, A. Yamazaki, Y. Otsuka, H. Yoshimura, Y. Kobayashi, and Y. Homma, Gold-filled apo-ferritin for investigation of singlewalled carbon nanotube growth on substrate. Chem. Phys. Lett. 445, 213 (2007).

147. Z. Zhang, L. Zhang, S. Senz, and M. Knez, Immobilization of apoferritin-templated seeds for Si nanowire growth. Chem. Vap. Deposition. 17, 149 (2011)

148. T. Li, S. Chattopadhyay, T. Shibata, R. E. Cook, J. T. Miller, N. Suthiwangcharoen, S. Lee, R. E. Winans, and B. Lee, Synthesis and characterization of Au-core Ag-shell nanoparticles from unmodified apoferritin. J. Mater. Chem. 22, 14458 (2012).

149. K. Yoshizawa, K. Iwahori, K. Sugimoto, and I. Yamashita, Fabrication of gold sulfide nanoparticles using the protein cage of apoferritin. Chem. Lett. 35, 1192 (2006).

150. J. W. Kim, A. E. Posey, G. D. Watt, S. H. Choi, and P. T. Lillehei, Gold nanoshell assembly on a ferritin protein employed as a biotemplate. J. Nanaosci. Nanotechnol. 10, 1771 (2010).

151. M. Suzuki, M. Abe, T. Ueno, S. Abe, T. Goto, Y. Toda, T. Akita, Y. Yamada, and Y. Watanabe, Preparation and catalytic reaction of $\mathrm{Au} / \mathrm{Pd}$ bimetallic nanoparticles in apo-ferritin. Chem. Commun. (Camb) 32, 4871 (2009).

152. Y. Shin, A. Dohnalkova, and Y. Lin, Preparation of homogeneous gold-silver alloy nanoparticles using the apoferritin cavity as a nanoreactor. J. Phys. Chem. C 114, 5985 (2010).

153. X. Liu, W. Wei, S. Huang, S. S. Lin, X. Zhang, C. Zhang, Y. Du, G. Ma, M. Li, S. Mann, and D. Ma, Bio-inspired protein-gold nanoconstruct with core-void-shell structure: Beyond a chemo drug carrier. J. Mater. Chem. B 1, 3136 (2013).

154. G. Liu, H. Wu, J. Wang, and Y. Lin, Apoferritin templated synthesis of metal phosphate nanoparticle labels for electrochemical immunoassay. Small 2, 1139 (2006).

155. G. Liu, H. Wu, A. Dohnalkova, and Y. Lin, Apoferritin-templated synthesis of encoded metallic phosphate nanoparticle tags. Anal. Chem. 79, 5614 (2007).

156. A. Abbaspour and A. Noori, Electrochemical detection of individual single nucleotide polymorphisms using monobasemodifiedapoferritin encapsulate dna noparticles. Biosens. Bioelectron 37, 11 (2012).

157. D. Dospivova, D. Hynek, P. Kopel, A. Bezdekova, J. Sochor, S. Krizkova, V. Adam, L. Trnkova, J. Hubalek, P. Babula, I. Provaznik, R. Vrba, and R. Kizek, Electrochemical behaviour of apoferritin encapsulating of silver(I) ions and its application for treatment of staphylococcus aureus. Int. J. Electrochem. Sci. 7, 6378 (2012).

158. O. Kasyutich, A. Ilari, A. Fiorillo, D. Tatchev, A. Hoell, and P. Ceci, Silver ion incorporation and nanoparticle formation inside the cavity of pyrococcus furiosus ferritin: Structural and size-distribution analyses. J. Am. Chem. Soc. 132, 3621 (2010).

159. J. M. Dominguez-Vera, N. Galvez, P. Sanchez, A. J. Mota, S. Trasobares, J. C. Hernandez, and J. J. Calvino, Size-controlled water-soluble Ag nanoparticles. Eur. J. Inorg. Chem. 2007, 4823 (2007).

160. B. Webb, J. Frame, Z. Zhao, M. L. Lee, and G. D. Watt, Molecular entrapment of small molecules within the interior of horse spleen ferritin. Arch. Biochem. Biophys. 309, 178 (1994).

161. J. C. Cutrin, S. G. Crich, D. Burghelea, W. Dastrù, and S. Aime, Curcumin/Gd loaded apoferritin: A novel "theranostic" agent to prevent hepatocellular damage in toxic induced acute hepatitis. Mol. Pharm. 10, 2079 (2013).

162. A. Makino, H. Harada, T. Okada, H. Kimura, H. Amano, H. Saji, M. Hiraoka, and S. Kimura, Effective encapsulation of a new cationic gadolinium chelate into apoferritin and its evaluation as an MRI contrast agent. Nanomed. Nanotechnol. Biol. Med. 7, 638 (2011).

163. S. Aime, L. Frullano, and S. G. Crich, Compartmentalization of a gadolinium complex in the apoferritin cavity: A route to obtain high relaxivity contrast agents for magnetic resonance imaging. Angew. Chem. Int. Ed. Engl. 41, 1017 (2002).

164. P. Sanchez, E. Valero, N. Gálvez, J. M. Domínguez-Vera, M. Marinone, G. Poletti, M. Corti, and A. Lascialfari, MRI relaxation properties of water-soluble apoferritin-encapsulated gadolinium oxide-hydroxide nanoparticles. Dalton Trans. 5, 800 (2009).

165. S. G. Crich, B. Bussolati, L. Tei, C. Grange, G. Esposito, S. Lanzardo, G. Camussi, and S. Aime, Magnetic resonance visualization of tumor angiogenesis by targeting neural cell adhesion molecules with the highly sensitive gadolinium-loaded apoferritin probe. Cancer Res. 66, 9196 (2006).

166. O. Vasalatiy, P. Zhao, S. Zhang, S. Aime, and A. D. Sherry, Catalytic effects of apoferritin interior surface residues on water proton exchange in lanthanide complexes. Contrast Med. Mol. Imaging 1, 10 (2006).

167. A. Chen, Y. Bao, X. Ge, Y. Shin, D. Du, and Y. Lin, Magnetic particle-based immunoassay of phosphorylated p53 using protein cage templated lead phosphate and carbon nanospheres for signal amplification. RSC Adv. 2, 11029 (2012).

168. D. Du, A. Chen, Y. Xie, A. Zhang, and Y. Lin, Nanoparticle based immunosensor with apoferritin template metallic phosphate label for quantification of phosphorylated acetylcholinesterase. Biosens. Bioelectron. 26, 3857 (2011).

169. L. Turyanska, T. D. Bradshaw, J. Sharpe, M. Li, S. Mann, N. R. Thomas, and A. Patanè, The biocompatibility of apoferritinencapsulated $\mathrm{PbS}$ quantum dots. Small 5, 1738 (2009).

170. L. Turyanska, T. D. Bradshaw, M. Li, P. Bardelang, W. C. Drewe, M. W. Fay, S. Mann, A. Patan, and N. R. Thomas, The differential effect of apoferritin-PbS nanocomposites on cell cycle progression in normal and cancerous cells. J. Mater. Chem. 22, 660 (2012).

171. B. Hennequin, L. Turyanska, T. Ben, A. M. Beltran, S. I. Molina, M. Li, S. Mann, A. Patane, and N. R. Thomas, Aqueous nearinfrared fluorescent composites based on apoferritin-encapsulated $\mathrm{PbS}$ quantum dots. Adv. Mater. 20, 3592 (2008).

172. H. Wu, J. Wang, Z. Wang, D. R. Fisher, and Y. Lin, Apoferritintemplated yttrium phosphate nanoparticle conjugates for radioimmunotherapy of cancers. J. Nanosci. Nanotechnol. 8, 2316 (2008).

173. K. Iwahori, T. Enomoto, H. Furusho, A. Miura, K. Nishio, Y. Mishima, and I. Yamashita, Cadmium sulfide nanoparticle synthesis in Dps protein from Listeria innocua. Chem. Mater. 19, 3105 (2007).

174. K. Iwahori, T. Morioka, and I. Yamashita, The optimization of CdSe nanoparticles synthesis in the apoferritin cavity. Phys. Status. Solidi. 203, 2658 (2006).

175. M. Naito, K. Iwahori, A. Miura, M. Yamane, and I. Yamashita, Circularly polarized luminescent CdS quantum dots prepared in a protein nanocage. Angew. Chem. Int. Ed. 49, 7006 (2010).

176. F. Yu, G. Li, B. Qu, and W. Cao, Electrochemical detection of DNA hybridization based on signal DNA probe modified with Au and apoferritin nanoparticles. Biosens. Bioelectron. 26, 1114 (2010). 
177. R. Xing, X. Wang, L. Yan, C. Zhang, Z. Yang, X. Wang, and Z. Guo, Fabrication of water soluble and biocompatible CdSe nanoparticles in apoferritin with the aid of EDTA. Dalton Trans. 10, 1710 (2009).

178. F. Yan, Y. Zhang, H. K. Yuan, M. K. Gregas, and T. Vo-Dinh, Apoferritin protein cages: A novel drug nanocarrier for photodynamic therapy. Chem. Commun. (Camb) 38, 4579 (2008).

179. F. Yan, Y. Zhang, K. S. Kim, H. K. Yuan, and T. Vo-Dinh, Cellular uptake and photodynamic activity of protein nanocages containing methylene blue photosensitizing drug. Photochem. Photobiol. 86, 662 (2010).

180. G. Liu, J. Wang, H. Wu, and Y. Lin, Versatile apoferritin nanoparticle labels for assay of protein. Anal. Chem. 78, 7417 (2006).

181. G. Liu, J. Wang, S. A. Lea, and Y. Lin, Bioassay labels based on apoferritin nanovehicles. Chembiochem. 7, 1315 (2006).

182. R. Xing, X. Wang, C. Zhang, Y. Zhang, Q. Wang, Z. Yang, and Z. Guo, Characterization and cellular uptake of platinum anticancer drugs encapsulated in apoferritin. J. Inorg. Biochem. 103, 1039 (2009).

183. Z. Yang, X. Wang, H. Diao, J. Zhang, H. Li, H. Sun, and Z. Guo, Encapsulation of platinum anticancer drugs by apoferritin. Chem. Commun. (Camb) 33, 3453 (2007).

184. $X$. T. Ji, L. Huang, and H. Q. Huang, Construction of nanometer cisplatin core-ferritin (NCC-F) and proteomic analysis of gastric cancer cell apoptosis induced with cisplatin released from the NCCF. J. Proteomics 75, 3145 (2012).

185. K. Iwahori, K. Yoshizawa, M. Muraoka, and I. Yamashita, Fabrication of $\mathrm{ZnSe}$ nanoparticles in the apoferritin cavity by designing a slow chemical reaction system. Inorg. Chem. 44, 6393 (2005).

186. Y. Suzumoto, M. Okuda, and I. Yamashita, Fabrication of zinc oxide semiconductor nanoparticles in the apoferritin cavity. Cryst. Growth Des. 12, 4130 (2012).

187. I. Szabo, S. G. Crich, D. Alberti, F. K. Kálmán, and S. Aime, Mn loaded apoferritin as an MRI sensor of melanin formation in melanoma cells. Chem. Commun. 48, 2436 (2012).

188. F. K. Kalman, S. Geninatti-Crich, and S. Aime, Reduction/dissolution of a beta-MnOOH nanophase in the ferritin cavity to yield a highly sensitive, biologically compatible magnetic resonance imaging agent. Angew. Chem. Int. Ed. Engl. 49, 612 (2010).

189. B. Sana, C. L. Poh, and S. A. Lim, manganese-ferritin nanocomposite as an ultrasensitive T2 contrast agent. Chem. Commun. 48, 862 (2012).

190. J. Fan, J. J. Yin, B. Ning, X. Wu, Y. Hu, M. Ferrari, G. J. Anderson, J. Wei, Y. Zhao, and G. Nie, Direct evidence for catalase and peroxidase activities of ferritin-platinum nanoparticles. Biomaterials 32, 1611 (2011).

191. L. Zhang, L. Laug, W. Münchgesang, E. Pippel, U. Gösele, M. Brandsch, and M. Knez, Reducing stress on cells with apoferritin-encapsulated platinum nanoparticles. Nano Lett. 10, 219 (2010).

192. X. Liu, W. Wei, C. Wang, H. Yue, D. Ma, C. Zhu, G. Mac, and Y. Du, Apoferritin-camouflaged Pt nanoparticles: Surface effects on cellular uptake and cytotoxicity. J. Mater. Chem. 21, 7105 (2011).

193. X. Liu, W. Wei, Q. Yuan, X. Zhang, N. Li, Y. Du, G. Ma, C. Yan, and D. Ma, Apoferritin- $\mathrm{CeO}_{2}$ nano-truffle that has excellent artificial redox enzyme activity. Chem. Commun. 48, 3155 (2012).

194. M. Okuda, Y. Suzumoto, and I. Yamashita, Bioinspired synthesis of homogenous cerium oxide nanoparticles and two- or threedimensional nanoparticle arrays using protein supramolecules. Cryst. Growth Des. 11, 2540 (2011).

195. H. Huang, Q. Yu, X. Peng, and Z. Ye, Mesoporous protein thin films for molecule delivery. J. Mater. Chem. 21, 13172 (2011).

196. A. Ma-Ham, H. Wu, J. Wang, X. Kang, Y. Zhang, and Y. Lin, Apoferritin-based nanomedicine platform for drug delivery: Equilibrium binding study of daunomycin with DNA. J. Mater. Chem. 21, 8700 (2011)
197. M. A. Kilic, E. Ozlu, and S. Calis, A novel protein-based anticancer drug encapsulating nanosphere: Apoferritin-doxorubicin complex. J. Biomed. Nanotechnol. 8, 508 (2012).

198. E. Simsek and M. A. Kilic, Magic ferritin: A novel chemoterapeutic encapsulation bullet. J. Magn. Magn. Mater. 293, 509 (2005).

199. Z. Zhen, W. Tang, H. Chen, X. Lin, T. Todd, G. Wang, T. Cowger, X. Chen, and J. Xie, RGD-Modified Apoferritin Nanoparticles for Efficient Drug Delivery to Tumors. ACS Nano 7, 4830 (2013).

200. Y. Zhang, Z. Tang, J. Wang, H. Wu, C. Lin, and Y. Lin, Apoferritin nanoparticle: A novel and biocompatible carrier for enzyme immobilization with enhanced activity and stability. J. Mater. Chem. 21, 17468 (2011)

201. N. Liao, Y. Zhuo, Y. Chai, Y. Xiang, Y. Cao, R. Yuan, and J. Han, Amplified electrochemiluminescent immunosensing using apoferritin-templated poly(ethylenimine) nanoparticles as coreactant. Chem. Commun. (Camb) 48, 7610 (2012).

202. A. Jaaskelainen, R. R. Harinen, T. Soukka, U. Lamminmaki, T. Korpimaki, and M. Virta, Biologically produced bifunctional recombinant protein nanoparticles for immunoassays. Anal. Chem. 80,583 (2008).

203. X. Liu, Z. Ye, W. Wei, Y. Du, J. Yuan, and D. Ma, Artificial luminescent protein as a bioprobe for time-gated luminescence Bioimaging. Chem. Commun. 47, 8139 (2011).

204. Y. Takezawa, P. Böckmann, N. Sugi, Z. Wang, S. Abe, T. Murakami, T. Hikage, G. Erker, Y. Watanabe, S. Kitagawa, and T. Ueno, Incorporation of organometallic Ru complexes into apoferritin cage. Dalton Trans. 40, 2190 (2011).

205. H. Wu, M. H. Engelhard, J. Wang, D. R. Fisher, and Y. Lin, Synthesis of lutetium phosphate-apoferritin coreshell nanoparticles for potential applications in radioimmunoimaging and radioimmunotherapy of cancers. J. Mater. Chem. 18, 1779 (2008).

206. H. Fukano, T. Takahashi, M. Aizawa, and H. Yoshimura, Synthesis of uniform and dispersive calcium carbonate nanoparticles in a protein cage through control of electrostatic potential. Inorg. Chem. 50, 6526 (2011).

207. M. Li, C. Viravaidya, and S. Mann, Polymer-mediated synthesis of ferritin-encapsulated inorganic nanoparticles. Small 3, 1477 (2007).

208. J. F. Hainfeld, Uranium-loaded apoferritin with antibodies attached: Molecular design for uranium neutron-capture therapy. Proc. Natl. Acad. Sci. USA 89, 11064 (1992).

209. W. Zhang, Y. Zhang, Y. Chen, S. Li, N. Gu, S. Hu, Y. Sun, X. Chen, and Q. Li, Prussian blue modified ferritin as peroxidase mimetics and its applications in biological detection. J. Nanosci. Nanotechnol. 13, 60 (2013).

210. G. A. R. Sola, M. G. Argüelles, D. L. Bottazzini, J. C. Furnari, I. G. Parada, A. Rojo, and H. V. Ruiz, Lutetium-177-EDTMP for bone pain palliation. Preparation, biodistribution and pre-clinical studies. Radiochimica. Acta 88, 157 (2000).

211. S. B. Brown, E. A. Brown, and I. Walker, The present and future role of photodynamic therapy in cancer treatment. Lancet Oncol. 5, 497 (2004)

212. Z. Zhen, W. Tang, C. Guo, H. Chen, X. Lin, G. Liu, B. Fei, X. Chen, B. Xu, and J. Xie, Ferritin nanocages to encapsulate and deliver photosensitizers for efficient photodynamic therapy against cancer. ACS Nano 7, 6988 (2013).

213. D. J. Weatherall, Developement of Iron Chelators for Clinical Use, edited by A. E. Martel, W. F. Anderson, and D. G. Badman, Elsevier, New York (1981), pp. 3-12.

214. M. Uchida, A. D. Willits, K. Muller, A. F. Willis, L. Jackiw, M. Jutila, M. Young, A. E. Porter, and T. Douglas, Intracellular distribution of macrophage targeting ferritin-iron oxide nanocomposite. Adv. Mater. 21, 458 (2009).

215. S. Fargion, A. L. Fracanzani, B. Brando, P. Arosio, S. Levi, and G. Fiorelli, Specific binding sites for H-ferritin on human 
lymphocytes: Modulation during cellular proliferation and potential implication in cell growth control. Blood 78, 1056 (1991).

216. Q. K. Liao, P. A. Kong, J. Gao, F. Y. Li, and Z. M. Qian, Expression of ferritin receptor in placental microvilli membrane in pregnant women with different iron status at mid-term gestation. Eur. J. Clin. Nutr. 55, 651 (2001).

217. D. Moss, S. Fargion, A. L. Fracanzani, S. Levi, M. D. Cappellini, P. Arosio, L. W. Powell, and J. W. Halliday, Functional roles of the ferritin receptors of human liver, hepatoma, lymphoid and erythroid cells. J. Inorg. Biochem. 47, 219 (1992).

218. M. S. Bretscher and J. N. Thomson, Distribution of ferritin receptors and coated pits on giant HeLa cells. EMBO J. 2, 599 (1983).

219. S. Fargion, P. Arosio, A. L. Fracanzani, V. Cislaghi, S. Levi, A. Cozzi, A. Piperno, and G. Fiorelli, Characteristics and expression of binding sites specific for ferritin $\mathrm{H}$-chain on human cell lines. Blood 71, 753 (1988).

220. C. D. San Martin, C. Garri, F. Pizarro, T. Walter, E. C. Theil, and M. T. Núñez, Caco-2 intestinal epithelial cells absorb soybean ferritin by mu2 (AP2)-dependent endocytosis. J. Nutr. 138, 659 (2008).

221. J. Y. Li, N. Paragas, R. M. Ned, A. Qiu, M. Viltard, T. Leete, I. R. Drexler, X. Chen, S. Sanna-Cherchi, F. Mohammed, D. Williams, C. S. Lin, K. M. Schmidt-Ott, N. C. Andrews, and J. Barasch, Scara5 is a ferritin receptor mediating non-transferrin iron delivery. Dev. Cell 16, 35 (2009).

222. T. T. Chen, L. Li, D. H. Chung, C. D. Allen, S. V. Torti, F. M. Torti, J. G. Cyster, C. Y. Chen, F. M. Brodsky, E. C. Niemi, M. C. Nakamura, W. E. Seaman, and M. R. Daws, TIM-2 is expressed on B cells and in liver and kidney and is a receptor for H-ferritin endocytosis. J. Exp. Med. 202, 955 (2005).

223. L. Li, C. J. Fang, J. C. Ryan, E. C. Niemi, J. A. Lebron, P. J. Bjorkman, H. Arase, F. M. Torti, S. V. Torti, M. C. Nakamura, and W. E. Seaman, Binding and uptake of H-ferritin are mediated by human transferrin receptor-1. Proc. Nat. Acad. Sci. USA 107, 3505 (2010).

224. J. W. Choi, Y. J. Kim, S. U. Kim, J. Min, and B. K. Oh, The fabrication of functional biosurface composed of iron storage protein, ferritin. Ultramicroscopy 108, 1356 (2008).

225. D. C. Zapien and M. A. Johnson, Direct electron transfer of ferritin adsorbed at bare gold electrodes. J. Electroanal. Chem. 494, 114 (2000).

226. R. C. Cherry, A. J. Bjornsen, and D. C. Zapien, Direct electron transfer of ferritin adsorbed at tin-doped indium oxide electrodes. Langmuir 14, 1971 (1998).

227. K. M. Shina, J. W. Leea, G. G. Wallace, and S. J. Kima, Electrochemical properties of SWNT/ferritin composite for bioapplications. Sens. Acuators. B 133, 393 (2008).

228. K. Won, M. J. Park, H. H. Yoon, and J. H. Kim, Immobilization of iron storage protein on a gold electrode based on self-assembled monolayers. Ultramicroscopy 108, 1342 (2008).

229. Y. Wu and S. Hu, Direct electron transfer of ferritin in dihexadecylphosphate on an Au film electrode and its catalytic oxidation toward ascorbic acid. Anal. Chim. Acta 527, 37 (2004).

230. A. Miura, R. Tsukamoto, S. Yoshii, I. Yamashita, Y. Uraoka, and T. Fuyuki, Non-volatile flash memory with discrete bionanodot floating gate assembled by protein template. Nanotechnology 19, 255201 (2008).

231. H. Kirimura, Y. Uraoka, T. Fuyuki, M. Okuda, and I. Yamashita, Study of low-temperature crystallization of amorphous Si films obtained using ferritin with $\mathrm{Ni}$ nanoparticles. Appl. Phys. Lett. 86, 262106 (2005).

232. G. Chen, X. Zhu, F. Meng, Z. Yu, and G. Li, Apoferritin as a bionanomaterial to facilitate the electron transfer reactivity of hemoglobin and the catalytic activity towards hydrogen peroxide. Bioelectrochemistry 72, 77 (2008).

233. J. Niemeyer, S. Abe, T. Hikage, T. Ueno, G. Erker, and Y. Watanabe, Non covalent insertion of ferrocenes into the protein shell of apo-ferritin. Chem. Commun. 48, 6519 (2008).

234. E. G. Heckert, A. S. Karakoti, S. Seal, and W. T. Self, The role of cerium redox state in the SOD mimetic activity of nanoceria. Biomaterials 29, 2705 (2008).

235. A. S. Karakoti, N. A. Monteiro-Riviere, R. Aggarwal, J. P. Davis, R. J. Narayan, W. T. Self, J. McGinnis, and S. Seal, Nanoceria as antioxidant: Synthesis and biomedical applications. JOM (1989) 60, 33 (2008).

236. J. M. Gorell, R. J. Ordidge, G. G. Brown, J. C. Deniau, N. M. Buderer, and J. A. Helpern, Increased iron-related MRI contrast in the substantia nigra in Parkinson's disease. Neurology 45, 1138 (1995).

237. V. Mani, K. C. Briley-Saebo, F. Hyafil, and Z. A. Fayad, Feasibility of in vivo identification of endogenous ferritin with positive contrast MRI in rabbit carotid crush injury using GRASP. Magn. Reson Med. 56, 1096 (2006).

238. G. Genove, U. Demarco, H. Xu, W. Goins, and E. Ahrens, A new transgene reporter for in vivo magnetic resonance imaging. Nat. Med. 11, 450 (2005).

239. B. Cohen, H. Dafni, G. Meir, A. Harmelin, and M. Neeman, Ferritin as an endogenous MRI reporter for noninvasive imaging of gene expression in C6 glioma tumors. Neoplasia 7, 109 (2005).

240. S. Matsumura, I. Aoki, T. Saga, and K. Shiba, A tumorenvironment-responsive nanocarrier that evolves its surface properties upon sensing matrix metalloproteinase- 2 and initiates agglomeration to enhance T2 relaxivity for magnetic resonance imaging. Mol. Pharmaceutics 8, 1970 (2011).

241. D. Kim, N. K. Chung, S. Allen, S. J. Tendler, and J. W. Park, Ferritin-based new magnetic force microscopic probe detecting $10 \mathrm{~nm}$ sized magnetic nanoparticles. ACS Nano 6, 241 (2012).

242. X. Peng, Q. Yu, Z. Yea, and I. Ichinose, Flexible ultrathin freestanding fluorescent films of CdSexS1_x/ZnS nanocrystalline and protein. J. Mater. Chem. 21, 4424 (2011).

243. G. Jutz and A. Boker, Bio-inorganic microcapsules from templating protein- and bionanoparticlestabilized Pickering emulsions. J. Mater. Chem. 20, 4299 (2010).

244. S. Wasilewski, D. Karelina, J. A. Berriman, and P. B. Rosenthal, Automatic magnification determination of electron cryomicroscopy images using apoferritin as a standard. J. Struct. Biol. 180, 243 (2012).

245. W. D. Moll and P. Guo, Grouping of ferritin and gold nanoparticles conjugated to pRNA of the phage phi29DNA-packaging motor. J. Nanosci. Nanotechnol. 7, 3257 (2007). 